\title{
Improved electrical conductivity and power factor in Sn and Se co-doped melt-grown $\mathrm{Bi}_{2} \mathrm{Te}_{3}$ single crystal
}

\author{
Ganesh Shridhar Hegde ${ }^{1}$, A. N. Prabhu ${ }^{1, *}$ (1), and M. K. Chattopadhyay ${ }^{2,3}$ \\ ${ }^{1}$ Department of Physics, Manipal Institute of Technology, Manipal Academy of Higher Education, Manipal 576104, India \\ ${ }^{2}$ Free Electron Laser Utilization Laboratory, Raja Ramanna Centre for Advanced Technology, Indore 452013, India \\ ${ }^{3}$ Homi Bhabha National Institute, Training School Complex, Anushakti Nagar, Mumbai 400094 , India
}

Received: 26 June 2021

Accepted: 31 August 2021

Published online:

9 September 2021

(C) The Author(s) 2021

\begin{abstract}
In the current work, growth and thermoelectric characterization of tin and selenium co-doped single crystal bismuth telluride have been carried out in the range of temperature $10-400 \mathrm{~K}$. The crystals show hexagonal crystal structure with $R \overline{3} m$ space group. The direction of growth, quality of the single crystals, the density of dislocation, and dopants effect on the inner plane structure of the crystals have been analyzed through high-resolution X-ray diffraction study. Energy dispersive analysis of X-rays approves the elemental composition, and field emission scanning electron microscopy shows uniform growth with micro precipitates on the surface of the crystals. Quasi degenerate and non-degenerate electrical resistivity is observed in the pristine and doped samples, respectively. Temperature-dependent Seebeck coefficient measurements confirm the $n$-type semiconducting nature of the pristine as well as doped samples. Temperaturedependent power factor of $\left(\mathrm{Bi}_{0.96} \mathrm{Sn}_{0.04}\right)_{2} \mathrm{Te}_{2.7} \mathrm{Se}_{0.3}$ is found to increase by 1.1 times, and electrical resistivity reduced by 3.3 times as compared to pristine $\mathrm{Bi}_{2} \mathrm{Te}_{3}$.
\end{abstract}

\section{Introduction}

Thermoelectric materials/devices have attracted huge global attention to waste heat utilization, converting heat energy into electrical energy and vice versa [1]. Bismuth chalcogenides are the vital materials utilized in low and near room temperature thermoelectric power converters [2]. The quality of the thermoelectric materials are estimated using the thermoelectric figure of merit $\left(Z T=\frac{S^{2} T}{K \rho}\right)$ where $S$ is the Seebeck coefficient, $T$ is the temperature, $K$ is the thermal conductivity and $\rho$ is the electrical resistivity [3]. $\mathrm{Bi}_{2} \mathrm{Te}_{3}$ and $\mathrm{Bi}_{2} \mathrm{Se}_{3}$ are considered suitable thermoelectric materials for low and near room temperature applications because of their electronically active antisite defects, which influence the co-factors like carrier concentration, mobility, bandgap, and activation energy $[4,5]$.

Zone melting/Bridgeman or Czochralsky techniques are mainly used for growing single crystal

Address correspondence to E-mail: ashwatha.prabhu@manipal.edu 
bismuth chalcogenides. The bismuth chalcogenide single crystals consist of a layered structure with a stacking order of $\mathrm{Te}^{(1)}-\mathrm{Bi}-\mathrm{Te}^{(2)}-\mathrm{Bi}-\mathrm{Te}^{(1)}$ [6]. It is important to note that $\mathrm{Bi}_{2} \mathrm{Te}_{3}$ crystals consist of $\mathrm{Bi}$ and Te hexagonal planes, which create quintuple layers in the unit cell [7]. Naturally, the point defects, low angle grains, and tilts are the major disorders in the melt-grown $\mathrm{Bi}_{2} \mathrm{Te}_{3}$ single crystals, and they have a significant influence on the thermoelectric properties. In addition, the inhomogeneity in solute distribution over the crystals enhances the scattering of electrons and phonons [8].

In some literature, it is noticed that there is an enhancement in thermoelectric performance by the dopants like In, Sn, Sb in bismuth telluride [9-11]. It is established that impurities generate the defect states, which stays in the valence band edge [12]. The partially filled impurity levels absorb electrons or holes with low impact on the Fermi-level. Hence impurity of Sn contains small band width and is considerably less hybridized with rest of the valence bands than the antisite $\mathrm{Bi}$ impurity level. Thus, grown single crystals possesses electrical homogeneity. $\mathrm{Sn}$ also behaves as acceptor-like impurity in $\mathrm{Bi}_{2} \mathrm{Te}_{3}$ generating quasi-local states situated on the background of conduction electrons.

As the chalcogen content is varied, the crystal could experience metallic conducting properties at different positions, which serves as the motivation for the co-doping of $\mathrm{Sn}$ and $\mathrm{Se}$ in $\mathrm{Bi}_{2} \mathrm{Te}_{3}$ by melt growth technique [9, 13-15]. Due to presence of large number of grain boundaries, polycrystalline bismuth chalcogenide sintered compounds fail to perform selective phonon scattering, unlike the single crystals. Selective phonon scattering found to decrease electrical resistivity. Previously we have reported the effect of Tin and Selenium co-doping in polycrystalline $\mathrm{Bi}_{2} \mathrm{Te}_{3}$ compound $[16,17]$. To maintain the stable temperature and good homogeneity in the elemental composition in the liquid phase, optimization of growth parameters like pulling rate $(2 \mathrm{~mm} / \mathrm{h})$, standard temperature profile with eight segments have been implemented. The present research investigation includes the high-resolution X-ray diffraction (HRXRD) characterizations such as Theta-2theta, rocking curve, and pie scans, which have provided the unique information about the symmetry and perfection of the grown single crystals. The current work is focused on the improved electrical resistivity and power factor in temperature range $10-400 \mathrm{~K}$ of
Sn and Se co-doped single crystal bismuth telluride grown by melt-grown technique.

\section{Experimental details}

\subsection{Growth of single crystal}

The growth of $\left(\mathrm{Bi}_{1-x} \mathrm{Sn}_{x}\right)_{2} \mathrm{Te}_{2.7} \mathrm{Se}_{0.3}$ single crystals have been carried out by melt growth technique. The precursor bismuth (Bi) (99.99\%), tin (Sn) (99.9\%), selenium (Se) (99.995\%), and tellurium (Te) (99.99\%) were weighed for $4 \mathrm{~g}$ in a stoichiometric ratio and ground in an agate mortar (open air-condition) for about $2 \mathrm{~h}$. Ampoules (length of $200 \mathrm{~mm}$ and a diameter of $14 \mathrm{~mm}$ with $50 \mathrm{~mm}$ conical shape at the end) were sealed in a $10^{-3}$ Torr vacuum. Residual argon gas was inserted in the ampoules at the pressure of $0.5 \mathrm{~kg} / \mathrm{cm}^{3}$ to get an inert atmosphere. The ampoules were tied to a motor and suspended in the crystal puller "Nanotech 1200" temperature gradient with the help of Kanthal string. The crystal puller furnace is used to melt the mixture by prearranged thermal profile between 30 and $850{ }^{\circ} \mathrm{C}$, with pulling rate of $2 \mathrm{~mm}$ per hour, at $600^{\circ} \mathrm{C}$ transition temperature. The ampoule holding the grown single crystal was then separated from the crystal puller unit. The grown crystals were isolated from the ampoule and cut into anticipated dimensions for characterization. The various stages involved in single crystal growth of $\left(\mathrm{Bi}_{1-x} \mathrm{Sn}_{x}\right)_{2} \mathrm{Te}_{2.7} \mathrm{Se}_{0.3}$ and the thermal profile are shown in Fig. 1a and b.

\subsection{Characterization}

Powder X-ray diffraction was utilized to know the purity, crystalline quality, and structure of finely powdered $\left(\mathrm{Bi}_{1-x} \mathrm{Sn}_{x}\right)_{2} \mathrm{Te}_{2.7} \mathrm{Se}_{0.3}$ single crystals. The experiments were performed using the "Rigaku Ultima IV" diffractometer in the range of $20^{\circ}-80^{\circ}$ utilizing X-ray $\mathrm{Cu} \mathrm{K \alpha}(1.54 \AA)$ radiation. The crystalline perfection, symmetries, dislocations, and dopants influence on the inner plane structure of the single crystals were determined using high-resolution X-ray diffraction (HR-XRD) study. Good quality single crystals of dimension $3 \mathrm{~mm} \times 4 \mathrm{~mm} \times 1 \mathrm{~mm}$ were scanned by means of "D8 Brüker Diffractometer" (source: $\mathrm{Cu} \mathrm{K \alpha}$; 1D fast detector, Double crystal monochromator with global mirror). Using the "Carl Zeiss Sigma" field emission scanning electron 


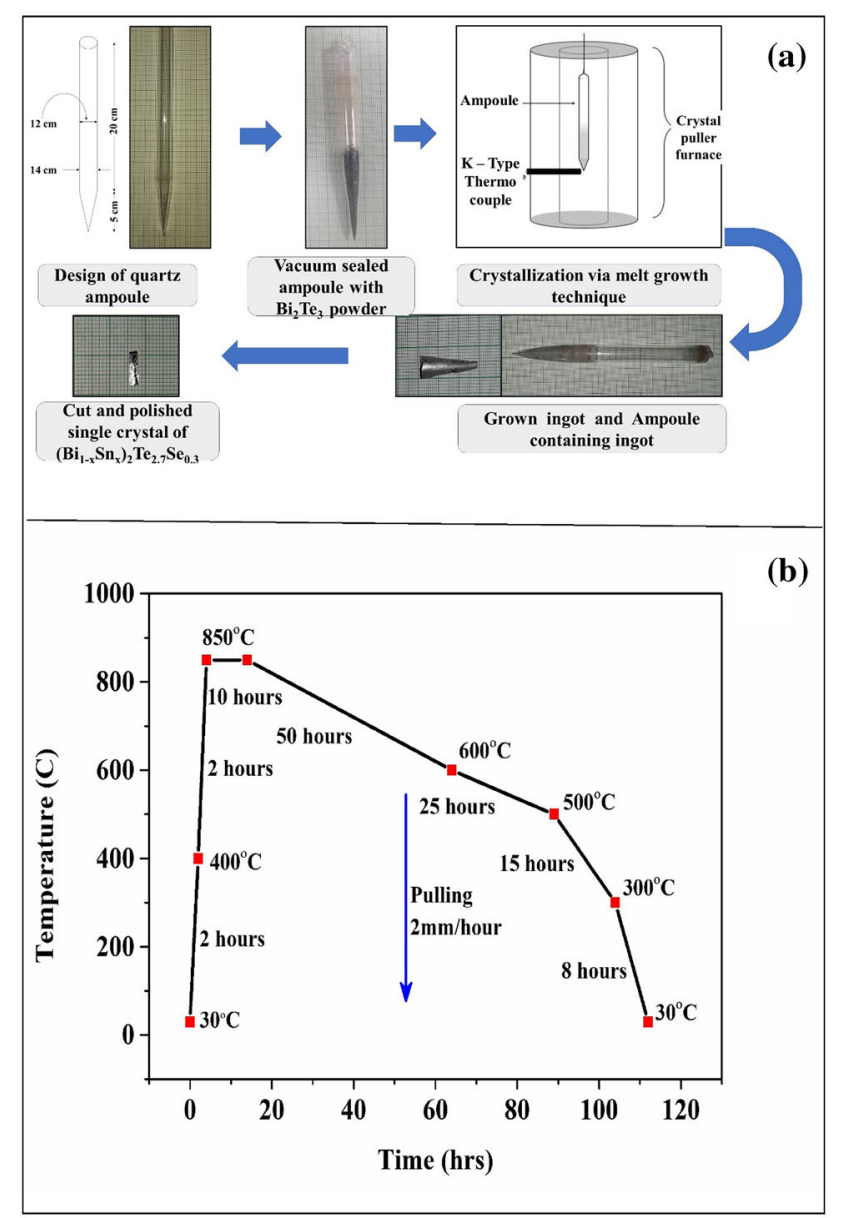

Fig. 1 a Schematic stages involved in growth of $\left(\mathrm{Bi}_{1-x} \mathrm{Sn}_{x}\right)_{2} \mathrm{Te}_{2.7} \mathrm{Se}_{0.3}$ single crystals. $\mathbf{b}$ Thermal profile maintained for growing $\left(\mathrm{Bi}_{1-x} \mathrm{Sn}_{x}\right) \mathrm{Te}_{2.7} \mathrm{Se}_{0.3}$ single crystals

microscope (FESEM), the surface morphological features of the single crystals were examined at the particle range of $1 \mu \mathrm{m}$ with a magnification of $35 \mathrm{kX}$. (20 $-120 \mu \mathrm{m}$ range with an accelerating voltage of $30 \mathrm{kV}$ with three detectors). To know the chemical composition of the grown single crystals, Energy dispersive X-ray analysis was carried out. The carrier concentration and mobility were determined at room temperature using the "Van der Pauw" technique, with the help of a Keithley $6220 \mathrm{~m}$. Electrical resistivity, thermal conductivity, and Seebeck coefficient were measured in the temperature range of 10-400 K using a Physical Property Measurement System (PPMS, Quantum Design).

\section{Results and discussion}

\subsection{Powder X-ray diffraction}

Figure 2 presents the XRD patterns of the $\left(\mathrm{Bi}_{1-x-}\right.$ $\left.\mathrm{Sn}_{x}\right)_{2} \mathrm{Te}_{2.7} \mathrm{Se}_{0.3}$ samples in the $2 \theta$ range of $20-80^{\circ}$. The (015) peak is the most dominant one in all samples, representing a single orientation and good crystalline nature [18]. Rietveld refinement was performed using "EXPO 2014" [Fig. 3] to know the deviation of the observed XRD peak patterns from the theoretical ones, and the values are given in Table 1. Systematic broadening and splitting of the peaks from the pristine to the co-doped $\left(\mathrm{Bi}_{0.98} \mathrm{Sn}_{0.04}\right)_{2} \mathrm{Te}_{2.7} \mathrm{Se}_{0.3}$ crystals were observed at the angles $28^{\circ}, 32^{\circ}, 70^{\circ}$. These changes result from the sharing of single lattice points by the prevailing crystal face (Fig. 4) [19]. The two additional reflections noticed around the plane (015) are due to the unveiling of twining orientations $[19,20]$. A systematic decrease in the crystallite size

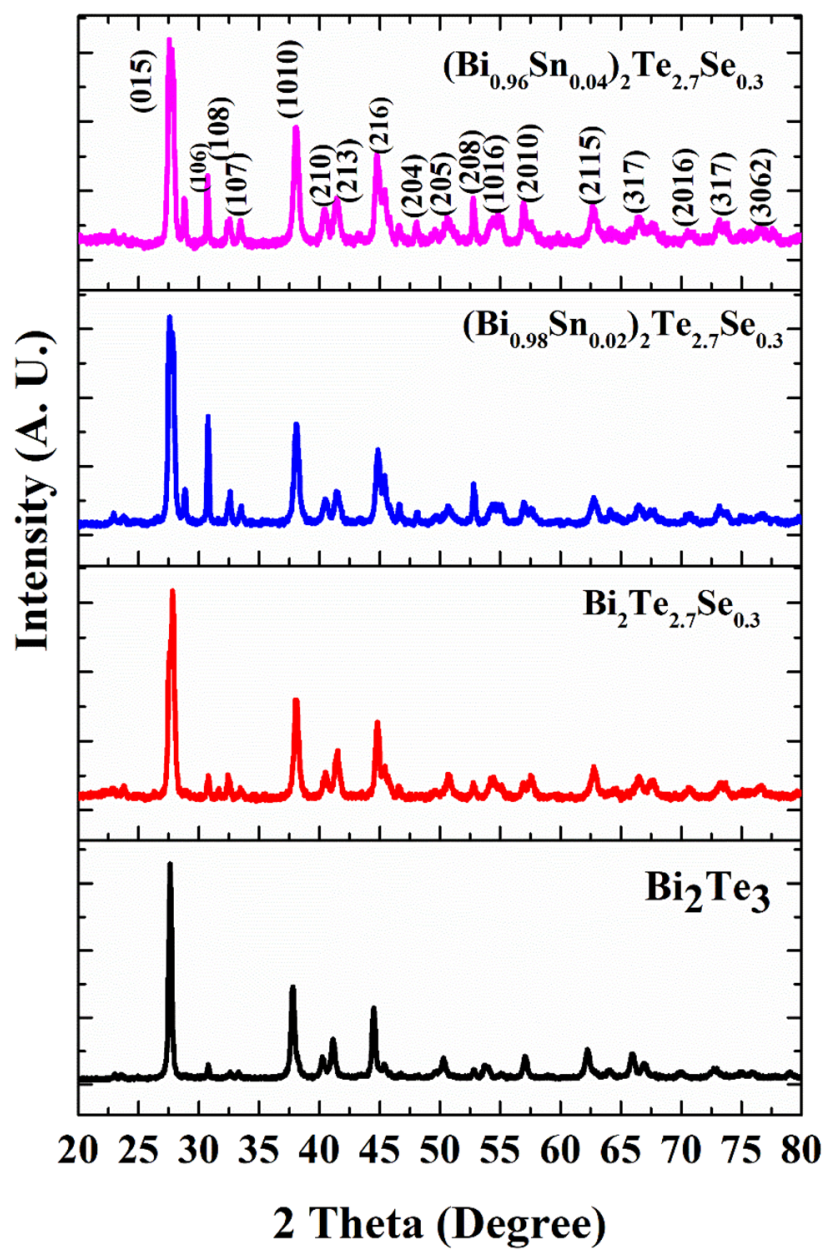

Fig. 2 XRD patterns of the $\left(\mathrm{Bi}_{1-x} \mathrm{Sn}_{x}\right)_{2} \mathrm{Te}_{2.7} \mathrm{Se}_{0.3}$ single crystals 
Fig. 3 Rietvield refinement images of

$\left(\mathrm{Bi}_{1-x} \mathrm{Sn}_{x}\right)_{2} \mathrm{Te}_{2.7} \mathrm{Se}_{0.3}$ single crystals

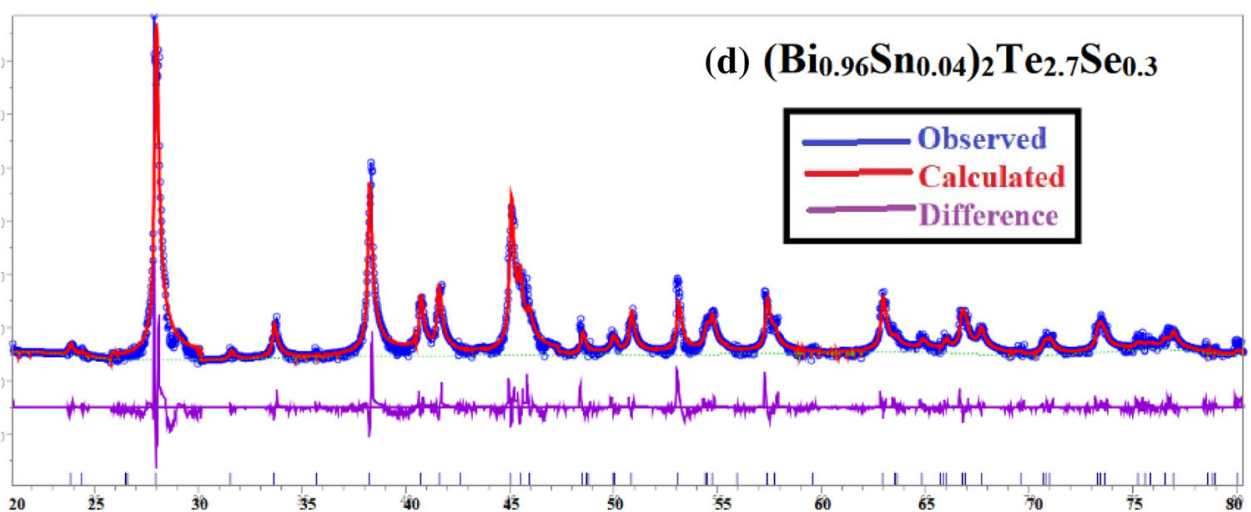

(c) $\left(\mathrm{Bi}_{0.98} \mathrm{Sn}_{0.02}\right)_{2} \mathrm{Te}_{2.7} \mathrm{Se}_{0.3}$

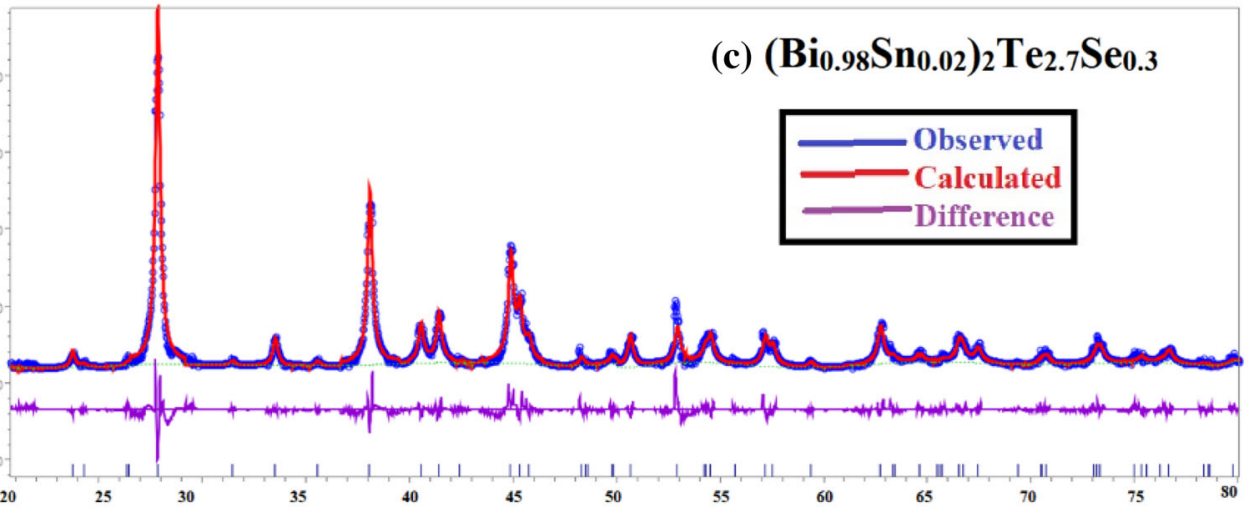

(b) $\mathrm{Bi}_{2} \mathrm{Te}_{2.7} \mathrm{Se}_{0.3}$

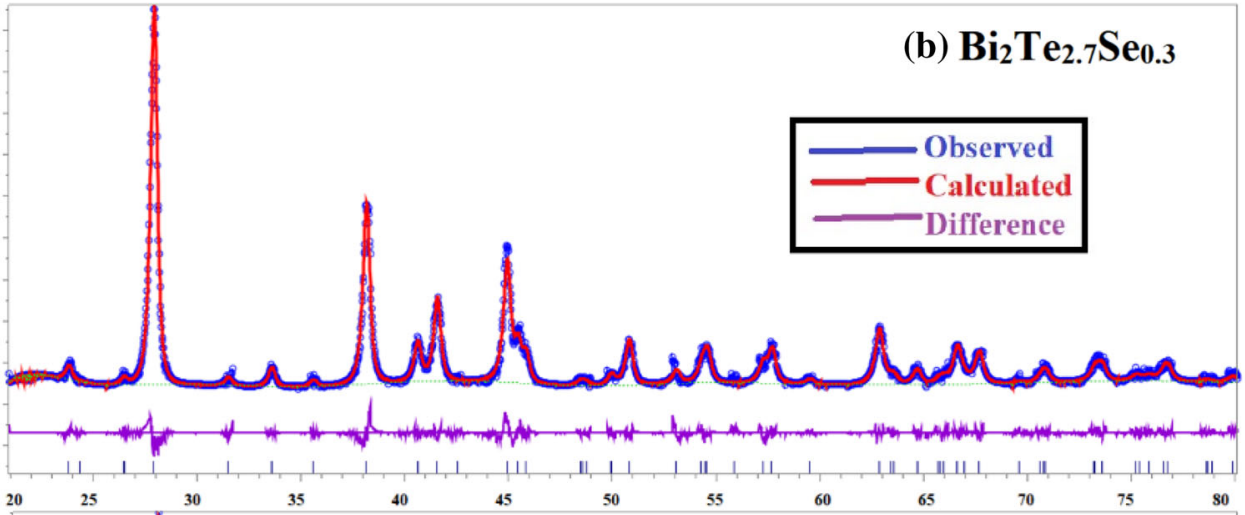

(a) $\mathrm{Bi}_{2} \mathrm{Te}_{3}$

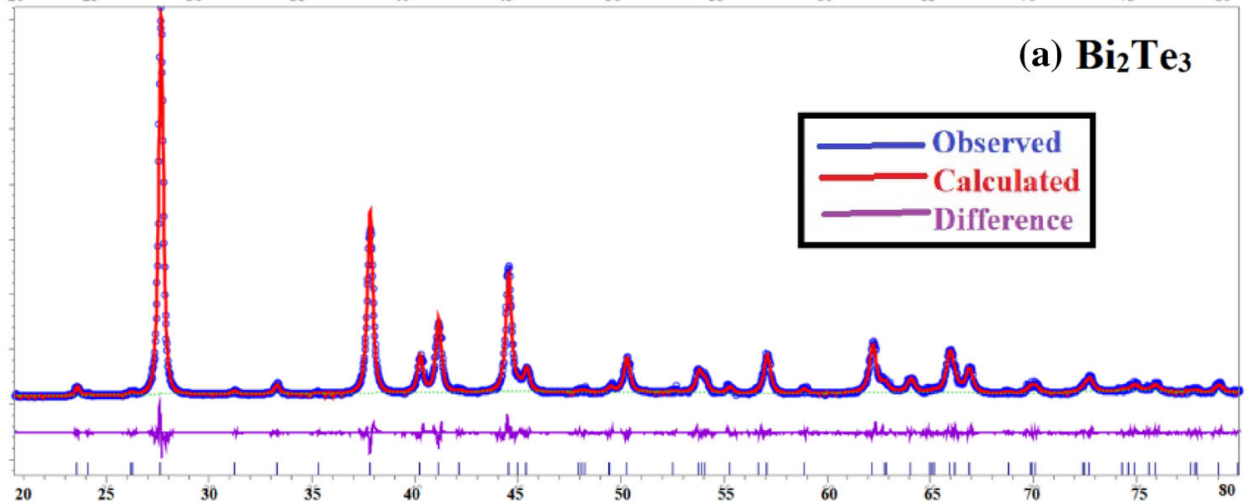

has been found with decreasing lattice parameters (Table 1), which is reported to be because of Sn atoms non-intercalation through Van der Waals interlayer
[21]. The crystallite size is determined using the Williamson-Hall formula [16]. $\left(\mathrm{Bi}_{1-x} \mathrm{Sn}_{x}\right)_{2} \mathrm{Te}_{2.7} \mathrm{Se}_{0.3}$ shows hexagonal crystal structure and $R \overline{3} \mathrm{~m}$ space 
Table 1 Single crystal $\left(\mathrm{Bi}_{1-x} \mathrm{Sn}_{x}\right)_{2} \mathrm{Te}_{2.7} \mathrm{Se}_{0.3}$ powder $\mathrm{XRD}$ analysis data

\begin{tabular}{|c|c|c|c|c|c|c|c|c|}
\hline Sample & $R_{\mathrm{p}}$ & $R_{\mathrm{wp}}$ & $R_{\mathrm{ep}}$ & $\chi^{2}$ & $\begin{array}{l}\text { crystallite } \\
\text { size(nm) }\end{array}$ & $\begin{array}{l}a=b \\
\AA \\
\pm 0.01\end{array}$ & $\begin{array}{l}\mathcal{C} \\
\AA \\
\pm 0.01\end{array}$ & $\begin{array}{l}\text { Lattice strain } \\
\left(10^{-3}\right)\end{array}$ \\
\hline $\mathrm{Bi}_{2} \mathrm{Te}_{3}$ & 13.0 & 12.0 & 7.0 & 2.9 & $46.3 \pm 0.2$ & 4.39 & 30.49 & $3.0 \pm 0.0002$ \\
\hline $\mathrm{Bi}_{2} \mathrm{Te}_{2.7} \mathrm{Se}_{0.3}$ & 14.0 & 11.0 & 6.8 & 3.3 & $34.1 \pm 0.3$ & 4.37 & 30.43 & $3.3 \pm 0.0003$ \\
\hline$\left(\mathrm{Bi}_{0.98} \mathrm{Sn}_{0.02}\right)_{2} \mathrm{Te}_{2.7} \mathrm{Se}_{0.3}$ & 10.4 & 14.0 & 7.0 & 3.4 & $19.4 \pm 0.1$ & 4.33 & 30.27 & $3.6 \pm 0.0001$ \\
\hline$\left(\mathrm{Bi}_{0.96} \mathrm{Sn}_{0.04}\right)_{2} \mathrm{Te}_{2.7} \mathrm{Se}_{0.3}$ & 8.2 & 12.0 & 7.1 & 2.8 & $15.5 \pm 0.1$ & 4.30 & 30.21 & $3.9 \pm 0.0001$ \\
\hline
\end{tabular}



Fig. 4 Splitting of the (015) peak of $\left(\mathrm{Bi}_{1-x} \mathrm{Sn}_{x}\right)_{2} \mathrm{Te}_{2.7} \mathrm{Se}_{0.3}$ single crystals

group with close-packed series of covalently bonded $\mathrm{Te}_{(\mathrm{Se})}-\mathrm{Bi}_{(\mathrm{Sn})}-\mathrm{Te}_{(\mathrm{Se})}$, when bismuth and tellurium are substituted by tin and selenium respectively in their sites [22]. The weak Van der Waals type of quintuple layers are formed by the interlayer forces [23]. The $\mathrm{Bi}_{2} \mathrm{Te}_{3}$ consists of an atomic layers sequence $\mathrm{Te}_{(1)}-\mathrm{Bi}-$ $\mathrm{Te}_{(2)}-\mathrm{Bi}-\mathrm{Te}_{(1)}\left(\mathrm{Bi}_{2} \mathrm{Te}_{3}\right)$. These layers are modified as $\mathrm{Te}_{(1)}-\mathrm{Bi}-\mathrm{Se}_{(2)}-\mathrm{Bi}-\mathrm{Te}_{(1)}$ in $\mathrm{Bi}_{2} \mathrm{Te}_{2.7} \mathrm{Se}_{0.3}$, and $\mathrm{Se}_{(1)}$ $\mathrm{Bi}_{(\mathrm{Sn})}-\mathrm{Se}_{(2)}-\mathrm{Bi}_{(\mathrm{Sn})}-\mathrm{Se}_{(1)}$ due to doping. A small but adequate quantity of $\mathrm{Te}$ atoms are able to complete each quintuple layer because of continuous inclusion of $\mathrm{Sn}$ and $\mathrm{Se}$ in $\mathrm{Bi}_{2} \mathrm{Te}_{3}$ [24]. As a result, these layers are introduced with more and more stacking faults. The Bi-Te phase decreases with the $\mathrm{Sn}-\mathrm{Te}, \mathrm{Sn}-\mathrm{Se}$, and Bi-Se phases investigated using "Profex 3.14" and is presented in Table 2 .

\subsection{High-resolution X-ray diffraction (HRXRD)}

HR-XRD investigation for the (015) plane, azimuthal $(\phi)$, and scan of the rocking curve for (0015) plane is carried out on $3 \mathrm{~mm} \times 4 \mathrm{~mm} \times 1 \mathrm{~mm}$ cleaved surface of single crystals. Figure 5 shows the $\theta-2 \theta$ measurement of scan for the crystals in between $10^{\circ}$ and $80^{\circ}$ measured at $2^{\circ}$ per minute scan rate. It is observed that the most significant peak in the $\mathrm{Bi}_{2} \mathrm{Te}_{3}$, $\mathrm{Bi}_{2} \mathrm{Te}_{2.7} \mathrm{Se}_{0.3}$, and $\left(\mathrm{Bi}_{0.96} \mathrm{Sn}_{0.04}\right)_{2} \mathrm{Te}_{2.7} \mathrm{Se}_{0.3}$ samples are due to the (006) plane in the ' $c$ ' direction, which corresponds to the desired and dominant phase in these samples. In $\left(\mathrm{Bi}_{0.98} \mathrm{Sn}_{0.02}\right)_{2} \mathrm{Te}_{2.7} \mathrm{Se}_{0.3}$ crystal, on the other hand, the most significant peak is due to the (0015) plane [25]. Various crystallographic orientations show somewhat different dynamics in the release of deposited energy due to a few random nucleation or growth. This significantly impacts selecting the process parameters, particularly the growth temperature and time required for achieving the desired properties at the final stage [26]. The sharpness of the peak due to the (0015) plane shows the high degree of crystallinity of the single crystals containing low angle grain boundaries [27-29]. Figure 6 shows the inner (015) $\theta-2 \theta$ scan for the between $20^{\circ}$ and $80^{\circ}$ measured at the rate of $2^{\circ}$ per minute. It is established that crystal growth has been taken along the (015) plane and all individual sample demonstrates dual intense sharp peaks at angles of about $27^{\circ}$ and $55^{\circ}$, which specifies the equivalent parallel planes of the crystals. The crystallite size values and strain of lattice are presented in Table 3. 
Table 2 The different phases of single crystal

\begin{tabular}{lllll}
\hline Sample name & \multicolumn{2}{l}{ Probable phases } & & \\
\cline { 2 - 5 } & $\mathrm{Bi}-\mathrm{Te}(\%)$ & $\mathrm{Bi}-\mathrm{Se}(\%)$ & $\mathrm{Sn}-\mathrm{Te}(\%)$ & $\mathrm{Sn}-\mathrm{Se}(\%)$ \\
\hline $\mathrm{Bi}_{2} \mathrm{Te}_{3}$ & 100 & - & - & - \\
$\mathrm{Bi}_{2} \mathrm{Te}_{2.7} \mathrm{Se}_{0.3}$ & 92.5 & 7.5 & - & - \\
$\left(\mathrm{Bi}_{0.98} \mathrm{Sn}_{0.02}\right)_{2} \mathrm{Te}_{2.7} \mathrm{Se}_{0.3}$ & 75.3 & $12 . .2$ & 10.2 & 2.3 \\
$\left(\mathrm{Bi}_{0.96} \mathrm{Sn}_{0.04}\right)_{2} \mathrm{Te}_{2.7} \mathrm{Se}_{0.3}$ & 65.0 & 15.0 & 12.0 & 8.0 \\
\hline
\end{tabular}

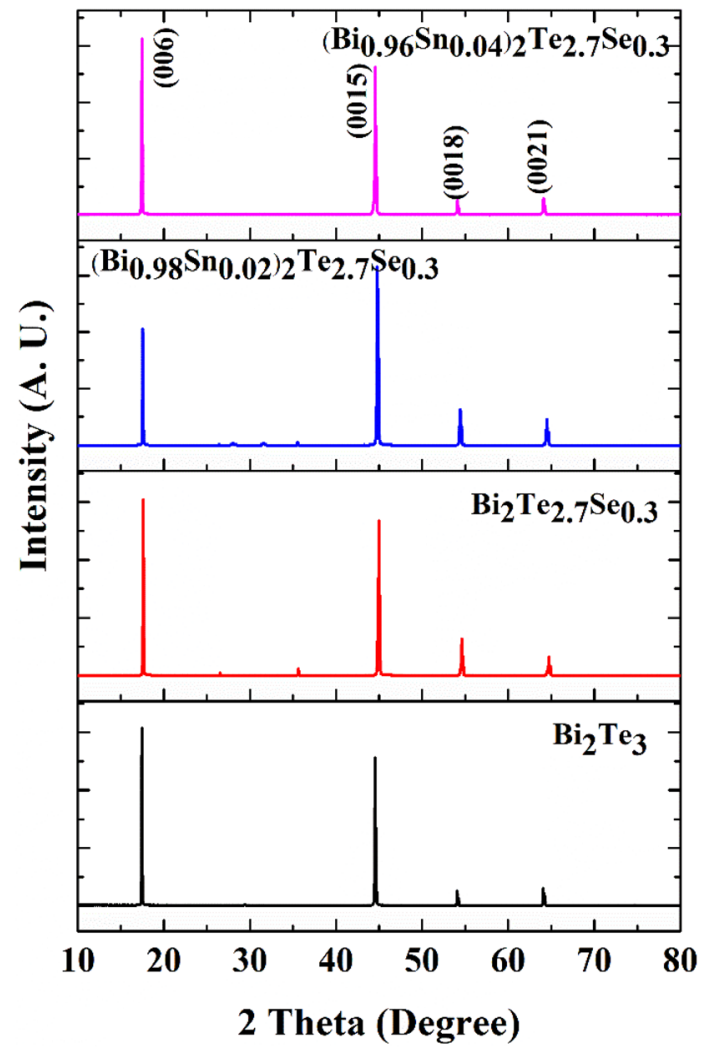

Fig. $5 \theta-2 \theta$ HR-XRD scan for the single crystals $\left(\mathrm{Bi}_{1-x} \mathrm{Sn}_{x}\right)_{2}$ $\mathrm{Te}_{2.7} \mathrm{Se}_{0.3}$

The $\phi$ scan for our crystals is performed in the range of $-180^{\circ}$ to $180^{\circ}$ at the rate of $2^{\circ}$ per minute for the plane (015). Figure 7 exhibits three peaks corresponding to the symmetry of the threefold (015) plane, representing in-plane orientation in the crystal. The intensity differences among pristine and doped samples are due to the variation in the population of domains $[29,30]$. Peak intensity discrepancies of the crystals in few regions result from a disorder of inplane orientation and the slight deviation between tilt angle and normal direction. Since the interval between the two peaks is $120^{\circ}$, it is inferred that the crystals possess a hexagonal structure.

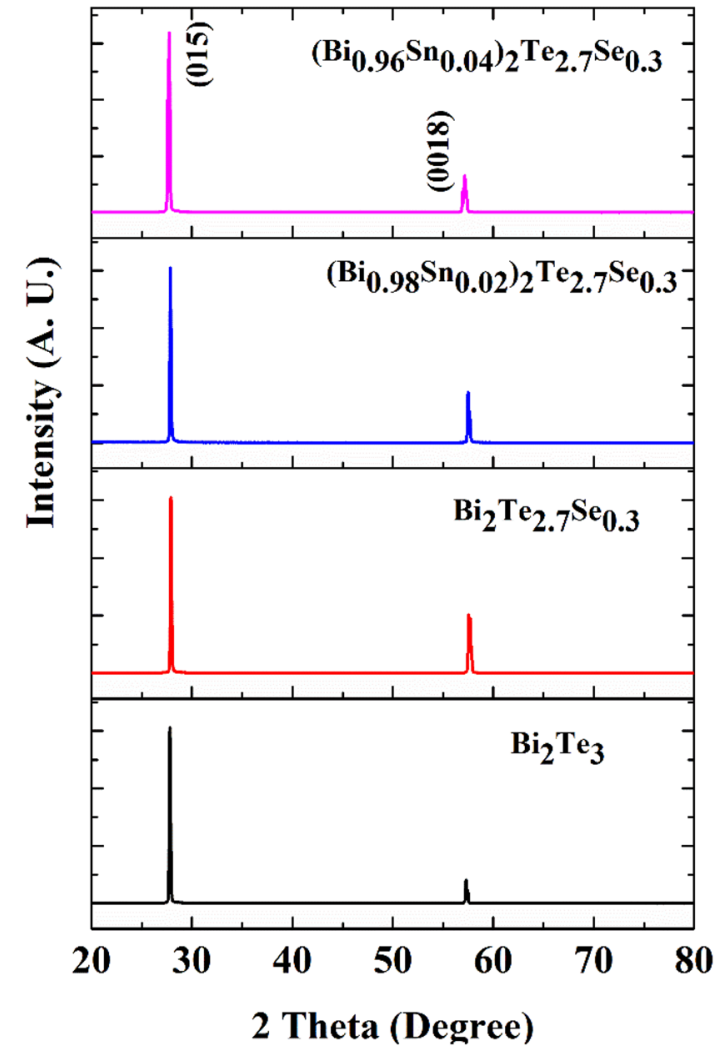

Fig. 6 The $\theta-2 \theta$ HR-XRD scan for the plane (015) of the single crystals $\left(\mathrm{Bi}_{1-x} \mathrm{Sn}_{x}\right)_{2} \mathrm{Te}_{2.7} \mathrm{Se}_{0.3}$

To know the perfection of the single crystals, a rocking curve scan has been carried out for (0015) plane in the $2 \theta$ between $16^{\circ}$ to $28^{\circ}$ at the rate of $2^{\circ}$ per minute, and the results are shown in Fig. 8. Lorentzian non-linear fitting of the curve has been used to validate the rocking curves of entire samples, where the theoretical curves are found to match quite well with the experimental curves. Lorentzian fitting factor $\left(R^{2}\right)$ values and FWHM $(\beta)$ are provided in Table 3. The crystals $\mathrm{Bi}_{2} \mathrm{Te}_{3}$ and $\left(\mathrm{Bi}_{0.98} \mathrm{Sn}_{0.02}\right)_{2-}$ $\mathrm{Te}_{2.7} \mathrm{Se}_{0.3}$ have sharp and fine peaks without any amorphous behaviors, whereas the crystals $\mathrm{Bi}_{2} \mathrm{Te}_{2.7-}$ $\mathrm{Se}_{0.3}$ and $\left(\mathrm{Bi}_{0.04} \mathrm{Sn}_{0.02}\right)_{2} \mathrm{Te}_{2.7} \mathrm{Se}_{0.3}$ have shown slight splitting of the peak. This is attributed to the 
Table 3 The HRXRD analysis data for the single crystals $\left(\mathrm{Bi}_{1-x} \mathrm{Sn}_{x}\right)_{2} \mathrm{Te}_{2.7} \mathrm{Se}_{0.3}$

\begin{tabular}{|c|c|c|c|c|c|c|}
\hline \multirow[t]{2}{*}{ Samples } & \multicolumn{2}{|c|}{$\begin{array}{l}\theta-2 \theta \text { scan for inner } \\
\text { plane }(015)\end{array}$} & \multicolumn{4}{|c|}{ Rocking curve scan plane (0015) } \\
\hline & $\begin{array}{l}\text { Crystallite } \\
\text { size } \\
(n m)\end{array}$ & $\begin{array}{l}\text { Lattice } \\
\text { Strain } \\
10^{-3}\end{array}$ & $\begin{array}{l}R^{2} \\
\text { (Lorentzian fitting } \\
\text { factor) }\end{array}$ & $\begin{array}{l}\beta \\
\text { (FWHM) }\end{array}$ & $\begin{array}{l}\text { Screw Dislocation } \\
\text { density } \\
\left(b_{s}\right) \\
\left(10^{12}\right) \mathrm{cm}^{-2}\end{array}$ & $\begin{array}{l}\text { Edge Dislocation } \\
\text { density } \\
\left(b_{e}\right) \\
\left(10^{14}\right) \mathrm{cm}^{-2}\end{array}$ \\
\hline $\mathrm{Bi}_{2} \mathrm{Te}_{3}$ & 138.4 & 9.1 & 0.96 & 0.14 & 2.2 & 9.8 \\
\hline $\mathrm{Bi}_{2} \mathrm{Te}_{2.7} \mathrm{Se}_{0.3}$ & 130.2 & 10.3 & 0.98 & 0.43 & 20.0 & 92.0 \\
\hline$\left(\mathrm{Bi}_{0.98} \mathrm{Sn}_{0.02}\right)_{2} \mathrm{Te}_{2.7} \mathrm{Se}_{0.3}$ & 91.3 & 15.2 & 0.98 & 0.13 & 1.9 & 8.2 \\
\hline$\left(\mathrm{Bi}_{0.96} \mathrm{Sn}_{0.04}\right)_{2} \mathrm{Te}_{2.7} \mathrm{Se}_{0.3}$ & 125.4 & 11.4 & 0.91 & 0.35 & 13.0 & 54.0 \\
\hline
\end{tabular}

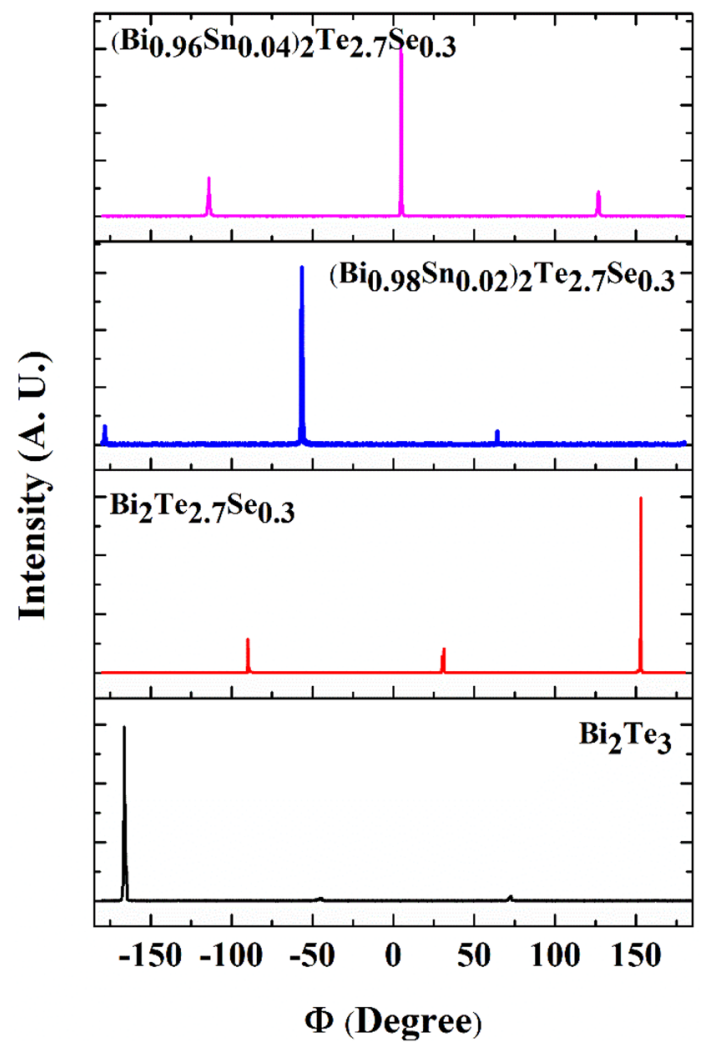

Fig. 7 The HR-XRD $\phi$ scan for the (015) plane of the $\left(\mathrm{Bi}_{1-x} \mathrm{Sn}_{x}\right)_{2} \mathrm{Te}_{2.7} \mathrm{Se}_{0.3}$ single crystals

occurrence of the low angle grain boundary with crystal domains misorientation [31-33]. The Sn and Se doping in $\left(\mathrm{Bi}_{0.98} \mathrm{Sn}_{0.02}\right)_{2} \mathrm{Se}_{2.7} \mathrm{Te}_{0.3}$ and $\left(\mathrm{Bi}_{0.96-}\right.$ $\left.\mathrm{Sn}_{0.04}\right)_{2} \mathrm{Se}_{2.7} \mathrm{Te}_{0.3}$ are predictable to produce point defects and mosaic orientation in the crystals [34-36]. The minor tilt angles generated through super-stoichiometric nature with ions $\mathrm{Bi}_{(\mathrm{Sn})}$ is the reason behind the rocking curve $\omega$ shift of individual crystal.

\subsection{Field emission scanning electron microscopy (FESEM)}

The characteristic surface morphological features of $\left(\mathrm{Bi}_{1-x} \mathrm{Sn}_{x}\right)_{2} \mathrm{Te}_{2.7} \mathrm{Se}_{0.3}$ samples are shown in Fig. 9, where the pristine $\mathrm{Bi}_{2} \mathrm{Te}_{3}$ shows homogeneous interfaces without any low angle grain boundary and porosity (Fig. 9a). The crystals $\mathrm{Bi}_{2} \mathrm{Te}_{2.7} \mathrm{Se}_{0.3}$ (Fig. 9b) shows tiny boundaries of tilt, which are ascribed to rise in the densities of dislocation and are determined by the relations [37]

$\rho_{\mathrm{s}}=\frac{\omega^{2}}{4.35 b_{\mathrm{s}}^{2}}$

$\rho_{\mathrm{e}}=\frac{\omega^{2}}{4.35 b_{\mathrm{e}}^{2}}$

where $b_{\mathrm{s}}$ is screw dislocation constant $(45 \mathrm{~nm})$, and $b_{\mathrm{e}}$ is edge dislocation constant $(2.17 \mathrm{~nm})$, and $\omega$ is the full width at half maximum intensity of rocking curve. It is observed that there are few black domains found on the surface of single crystal $\left(\mathrm{Bi}_{0.98} \mathrm{Sn}_{0.02}\right)_{2-}$ $\mathrm{Te}_{2.7} \mathrm{Se}_{0.3}$. This is due to the interface created by the micro precipitate formed due to Se and Te particles throughout the melt growth process (Fig. 9c). As Se is inserted into $\mathrm{Bi}_{2} \mathrm{Te}_{3}$ matrix, unrestrained melt mixture in ampoule is seen due to peritectic reactions [38]. However, due to Se evaporation, few micro precipitates and microdots are observed in the $\left(\mathrm{Bi}_{0.96} \mathrm{Sn}_{0.04}\right) \mathrm{Te}_{2.7} \mathrm{Se}_{0.3}$ sample [39]. Moreover, some small white patches of coarse grains are observed in the $\left(\mathrm{Bi}_{0.96} \mathrm{Sn}_{0.04}\right)_{2} \mathrm{Te}_{2.7} \mathrm{Se}_{0.3}$ crystal because of the thermal and mechanical fluctuations in the crystal melting process (Fig. 9c) [40-43]. 
Fig. 8 The HR-XRD scan of rocking curve for plane (0015) of single crystals. a $\mathrm{Bi}_{2} \mathrm{Te}_{3}$, b $\mathrm{Bi}_{2} \mathrm{Te}_{2.7} \mathrm{Se}_{0.3}$,

c $\left(\mathrm{Bi}_{0.98} \mathrm{Sn}_{0.02}\right)_{2} \mathrm{Te}_{2.7} \mathrm{Se}_{0.3}$ and d $\left(\mathrm{Bi}_{0.96} \mathrm{Sn}_{0.04}\right)_{2} \mathrm{Te}_{2.7} \mathrm{Se}_{0.3}$
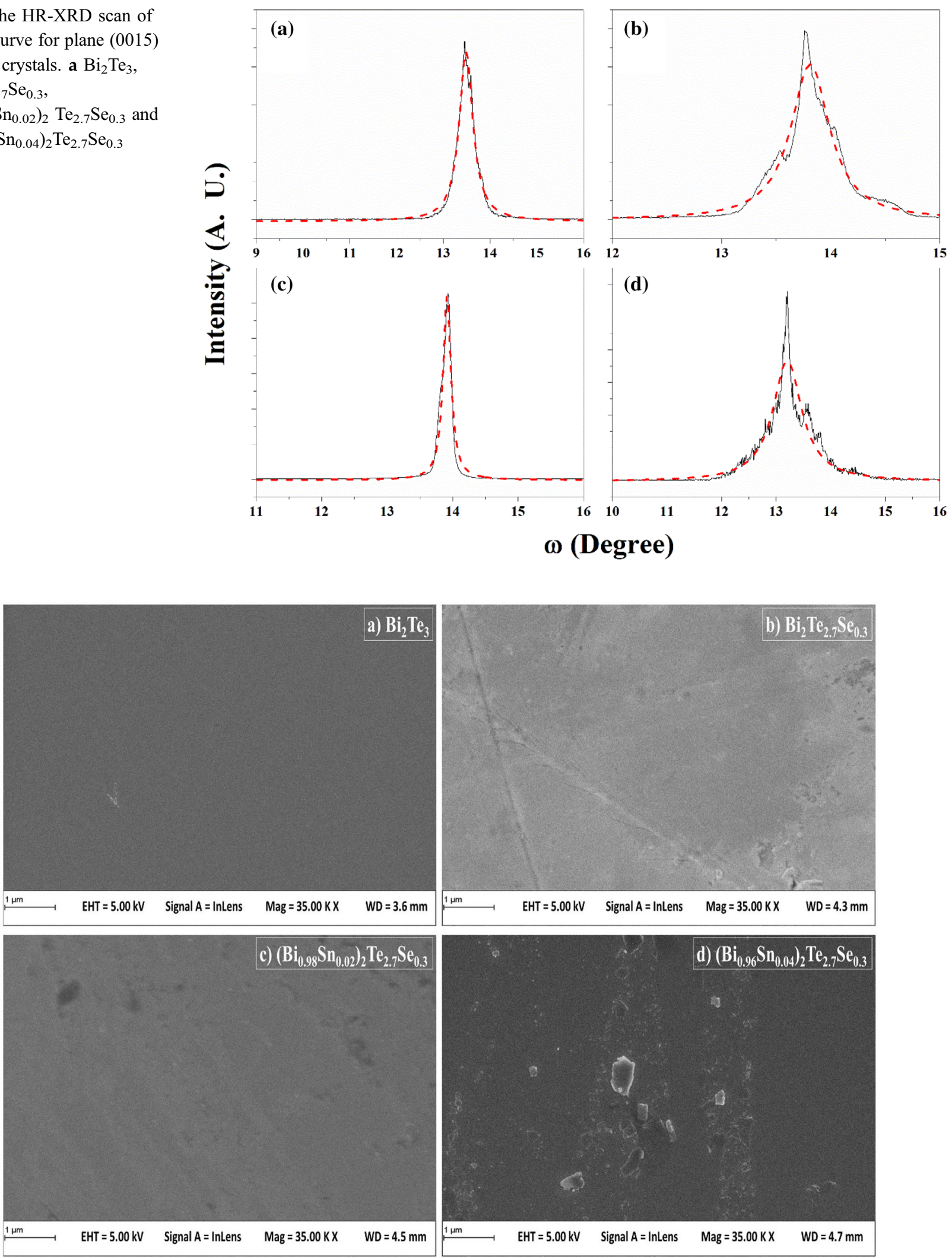

Fig. 9 FESEM images of $\mathbf{a} \mathrm{Bi}_{2} \mathrm{Te}_{3}, \mathbf{b} \mathrm{Bi}_{2} \mathrm{Te}_{2.7} \mathrm{e}_{0.3}, \mathbf{c}\left(\mathrm{Bi}_{0.98} \mathrm{Sn}_{0.02}\right)_{2} \mathrm{Te}_{2.7} \mathrm{Se}_{0.3}$ and $\mathbf{d}\left(\mathrm{Bi}_{0.98} \mathrm{Sn}_{0.02}\right)_{2} \mathrm{Te}_{2.7} \mathrm{Se}_{0.3}$ single crystals 


\subsection{Energy dispersive $\mathrm{X}$-ray analysis (EDAX)}

EDAX has been carried out to determine the chemical composition of the crystals, and the images are shown in Fig. 10. The pristine $\mathrm{Bi}_{2} \mathrm{Te}_{3}$ is found to contain bismuth and tellurium (Fig. 10a), whereas the $\mathrm{Bi}_{2} \mathrm{Te}_{2.7} \mathrm{Se}_{0.3}$ is found to contain selenium along with the bismuth and tellurium (Fig. 10b). Figure 10c, d establish the occurrence of tin in the $\left(\mathrm{Bi}_{1-x} \mathrm{Sn}_{x}\right)_{2-}$ $\mathrm{Te}_{2.7} \mathrm{Se}_{0.3}$ samples. The expected/nominal composition matches well with the measured elemental composition of the studied crystals, as shown in Table 4. The EDAX results confirm that the atomic percentage of $\mathrm{Sn}$ in crystal $\left(\mathrm{Bi}_{0.98} \mathrm{Sn}_{0.02}\right)_{2} \mathrm{Te}_{2.7} \mathrm{Se}_{0.3}$ and $\left(\mathrm{Bi}_{0.96} \mathrm{Sn}_{0.04}\right)_{2} \mathrm{Te}_{2.7} \mathrm{Se}_{0.3}$ are $0.97 \%$ and $1.74 \%$, respectively. On the other hand, the atomic percentage of Se in $\mathrm{Bi}_{2} \mathrm{Te}_{2.7} \mathrm{Se}_{0.3},\left(\mathrm{Bi}_{0.98} \mathrm{Sn}_{0.02}\right)_{2} \mathrm{Te}_{2.7} \mathrm{Se}_{0.3}$ and $\left(\mathrm{Bi}_{0.96-}\right.$ $\left.\mathrm{Sn}_{0.04}\right)_{2} \mathrm{Te}_{2.7} \mathrm{Se}_{0.3}$ are $10.31 \%, 10.82 \%$ and $12.46 \%$, respectively.

\subsection{Electrical resistivity}

The temperature dependence of electrical resistivity $\rho(T)$ of the $\left(\mathrm{Bi}_{1-x} \mathrm{Sn}_{x}\right)_{2} \mathrm{Te}_{2.7} \mathrm{Se}_{0.3}$ samples is presented in Fig. 11 between 10 and 395 K. Overall, and the $\rho(T)$ values decrease systematically from the pristine to the co-doped samples. The pristine $\mathrm{Bi}_{2} \mathrm{Te}_{3}$ has the highest electrical resistivity with quasi degenerate semiconducting behavior. Initially, there is an enhancement in the value of electrical resistivity with a rise in temperature from 10 to $250 \mathrm{~K}$ due to the low mobility of the opposing charges around another donor atom, which causes direct cation-cation interaction of homopolar $\mathrm{Bi}-\mathrm{Bi}$ bonds [44]. The electrons fail to conduct significantly unless the temperature is raised sufficiently (above $250 \mathrm{~K}$ ). With sufficient energy supply beyond $250 \mathrm{~K}$, the negative charge mingles with extra electrons of all the donor atoms, leading to the usual semiconducting behavior at higher temperatures. The $\mathrm{Te}_{\mathrm{Bi}}$ formed in the lattice due to the vaporization of Te increases the concentration of Te vacancies $\left[\mathrm{V}_{\mathrm{Te}}\right][45,46]$.

Additionally, point defects are created by introducing Se in the Te sites in $\mathrm{Bi}_{2} \mathrm{Te}_{2.7} \mathrm{Se}_{0.3}$, and antisite defects of $\mathrm{Bi}$ on $\mathrm{Te}_{(\mathrm{Se})}$ sites are also formed [47]. The substituted Se atom in the anion sublattice of Te sites generates anion vacancies. The added dopant $\mathrm{Sn}$ $(0.02,0.04)$ exists in the form of $\mathrm{Sn}_{\mathrm{Bi}}$. As a result, there
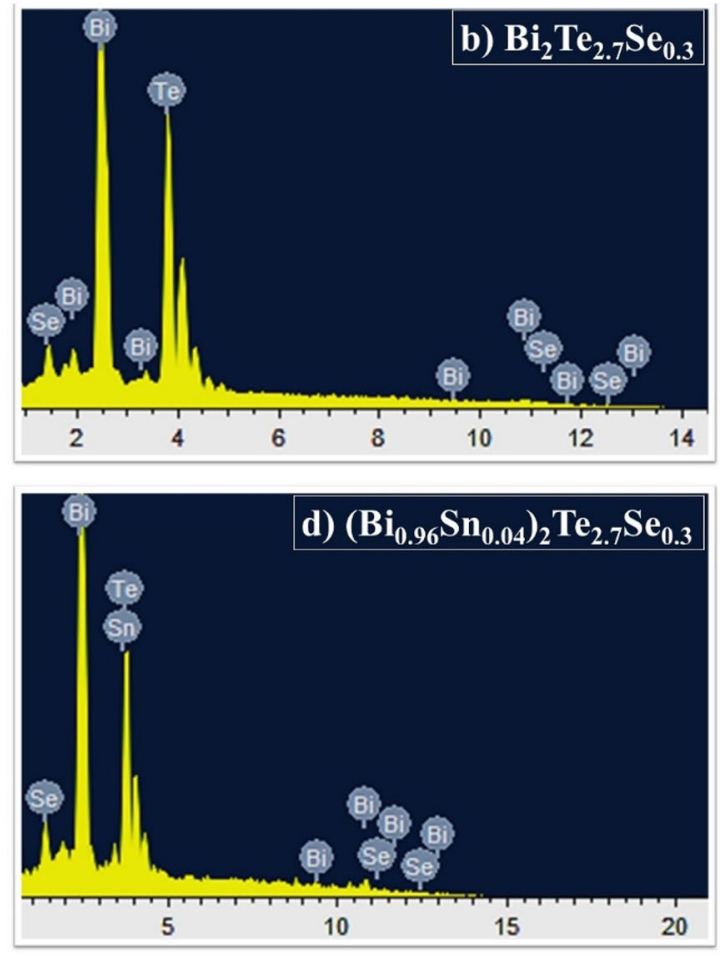

Energy (keV)

Fig. 10 The EDAX images of (i) $\mathrm{Bi}_{2} \mathrm{Te}_{3}$, (ii) $\mathrm{Bi}_{2} \mathrm{Te}_{2.7} \mathrm{Se}_{0.3}$, (iii) $\left(\mathrm{Bi}_{0.98} \mathrm{Sn}_{0.02}\right)_{2} \mathrm{Te}_{2.7} \mathrm{Se}_{0.3}$, and (iv) $\left(\mathrm{Bi}_{0.96} \mathrm{Sn}_{0.04}\right)_{2} \mathrm{Te}_{2.7} \mathrm{Se}_{0.3}$ single crystals 
Table 4 Elemental composition of the $\left(\mathrm{Bi}_{1-x} \mathrm{Sn}_{x}\right)_{2} \mathrm{Te}_{2.7} \mathrm{Se}_{0.3}$ single crystals

\begin{tabular}{llcr}
\hline Samples & Elements & Nominal atomic \% & Observed atomic \% \\
\hline $\mathrm{Bi}_{2} \mathrm{Te}_{3}$ & $\mathrm{Bi}$ & 40.00 & 39.76 \\
& $\mathrm{Te}$ & 60.00 & 60.24 \\
$\mathrm{Bi}_{2} \mathrm{Te}_{2.7} \mathrm{Se}_{0.3}$ & $\mathrm{Bi}$ & 40.00 & 40.64 \\
& $\mathrm{Te}$ & 54.00 & 53.24 \\
& $\mathrm{Se}$ & 6.00 & 6.12 \\
$\left(\mathrm{Bi}_{0.98} \mathrm{Sn}_{0.02}\right)_{2} \mathrm{Te}_{2.7} \mathrm{Se}_{0.3}$ & $\mathrm{Bi}$ & 39.60 & 38.52 \\
& $\mathrm{Sn}$ & 0.40 & 0.38 \\
& $\mathrm{Te}$ & 54.00 & 54.47 \\
& $\mathrm{Se}$ & 6.00 & 6.63 \\
$\left(\mathrm{Bi}_{0.96} \mathrm{Sn}_{0.04}\right)_{2} \mathrm{Te}_{2.7} \mathrm{Se}_{0.3}$ & $\mathrm{Bi}$ & 39.20 & 38.28 \\
& $\mathrm{Sn}$ & 0.80 & 0.68 \\
& $\mathrm{Te}$ & 54.00 & 53.43 \\
& $\mathrm{Se}$ & 6.00 & 7.61 \\
\hline
\end{tabular}

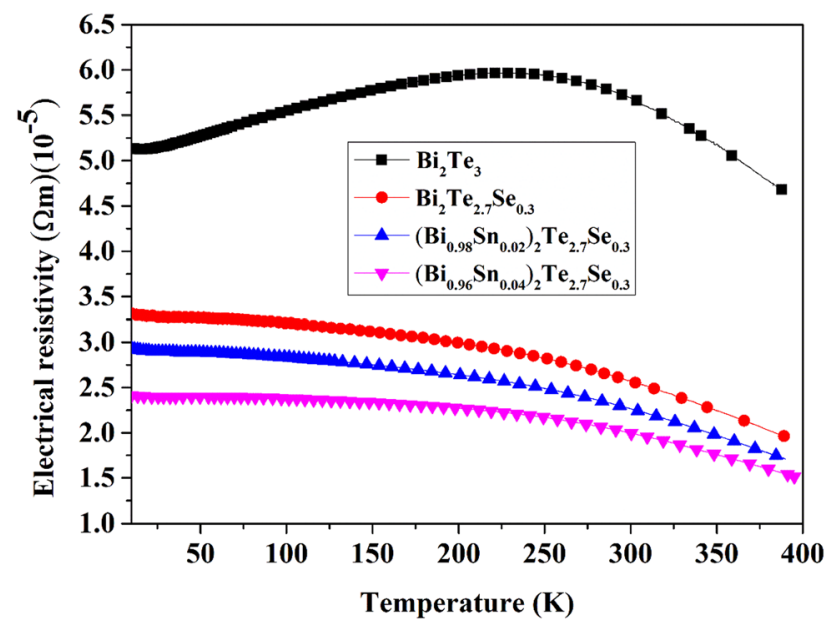

Fig. 11 Temperature-dependent electrical resistivity of $\left(\mathrm{Bi}_{1-x} \mathrm{Sn}_{x}\right)_{2}$ $\mathrm{Te}_{2.7} \mathrm{Se}_{0.3}$ single crystals

is an increase in the antisite defect of $\mathrm{Sn}_{\mathrm{Bi}}$ on Te $\mathrm{Te}_{\mathrm{Se}} . \mathrm{Sn}$ easily replaces $\mathrm{Bi}$ with the polar bond because of the electronegativity difference between them [48]. The electrical transport properties of polycrystalline samples are governed by more grain boundaries. As a result, the uniform heat flow and the movement of electrons/holes through a sample consisting of randomly oriented polycrystalline grains is difficult. Whereas, the single crystals are having few grain boundaries, divide both the electrical and thermal conductivities along the two equivalent principal directions [49]. On the other side, the carrier concentration of the samples are modified by the donorlike effect produced by heavy deformation, where $V_{B i}^{\prime \prime \prime}, \quad V_{\bar{T} e}$ are the vacancies of $\mathrm{Bi}_{(\mathrm{Sn})}$ and $\mathrm{Te}_{(\mathrm{Se})}$, respectively. Another positively charged anion vacancy $V_{\ddot{S} e}$ induces more negative carrier in the lattice which changes the electrical properties drastically [50]. This leads to the reduction of electrical resistivity by 3.3 times for $\left(\mathrm{Bi}_{0.96} \mathrm{Sn}_{0.04}\right)_{2} \mathrm{Te}_{2.7} \mathrm{Se}_{0.3}$ in comparison with the pristine sample at $395 \mathrm{~K}$. Antisite defect equation is provided by

$$
\begin{aligned}
\mathrm{Bi}_{2} \mathrm{Te}_{3}+2 x \mathrm{Sn}= & (2-2 x) \mathrm{Bi}_{\mathrm{Bi}}^{\mathrm{X}}+(3-y) \mathrm{Te}_{\mathrm{Te}}^{x}+2 x \mathrm{Sn}_{\mathrm{Bi}}^{-} \\
& +2 x \mathrm{Bi}+2 x h^{+}+(y) \mathrm{Te}+y V_{\mathrm{Te}}^{2+} \\
& +2 y e^{-}
\end{aligned}
$$

Mott's variable range hopping (VRH) model (Fig. 12) is utilized to study conduction in hopping near Fermi-level in localized states at low temperatures $(10-40 \mathrm{~K})$. The electrons in a preliminary localized state get sufficient thermal energy to hop to the closest localized state [51]. When the internal microscopic disorder is high, tunneling of electrons

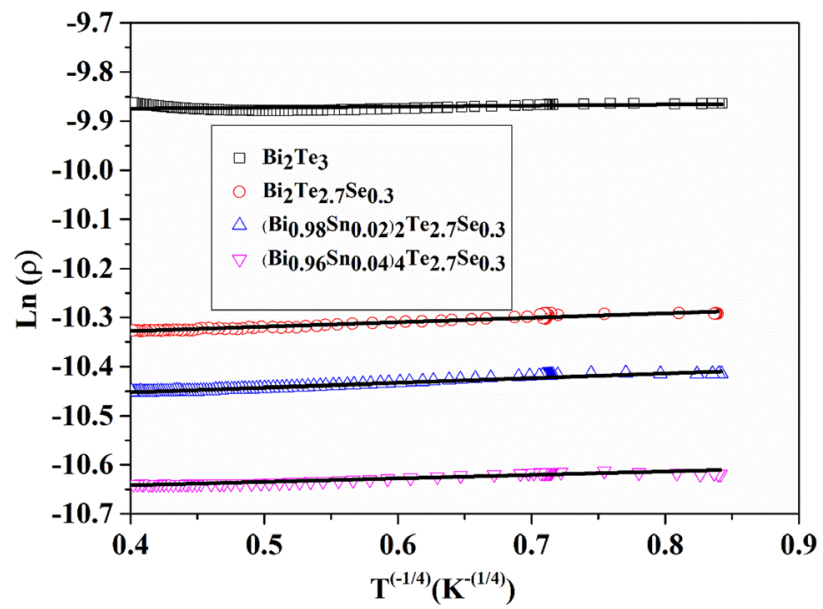

Fig. 12 The plot of $\ln (\rho)$ versus $T^{-1 / 4}$ for single crystals $\left(\mathrm{Bi}_{1-x} \mathrm{Sn}_{x}\right)_{2} \mathrm{Te}_{2.7} \mathrm{Se}_{0.3}$ in the range $10-40 \mathrm{~K}$ 
between the nearest sites is also energetically unfavorable [52]. The electrical resistivity in the VRH model is expressed as

$\rho=\rho_{0} \exp \left(\frac{T_{0}}{T}\right)^{1 / 4}$

where $T_{0}$ is the characteristic temperature and $\rho_{0}$ is the pre-exponential factor. The characteristic temperature is given by

$T_{0}=\left(\frac{18 \alpha^{3}}{k_{B} N\left(E_{F}\right)}\right)$

where $N\left(E_{\mathrm{F}}\right)$ is the density of state at the Fermi level, $k_{\mathrm{B}}$ is the Boltzmann constant, and $\alpha$ is average localization length $\left(19 \mathrm{~nm}^{-1}\right)$, calculated using the relation

$\alpha=\frac{q^{2} 0.025 \rho}{\hbar}$.

Table 5 presents the calculation results of density of state (DOS) $N\left(E_{F}\right)$ values, calculated using Eq. 5 (Fig. 13).

The model of small polaron hopping (SPH) is applied for analyzing electrical resistivity data in the range $140-250 \mathrm{~K}$, using the expression [53]

$\rho=\rho_{0} T \exp \left(\frac{E_{A}}{k_{B} T}\right)$

where $E_{A}$ is the activation energy. The plot of $\ln (\rho /$ $T)$ versus $1 / T$ shown in Fig. 14 suggests that thermally triggered small polarons are accountable for conduction in hopping at higher temperature region in the $\left(\mathrm{Bi}_{1-x} \mathrm{Sn}_{x}\right)_{2} \mathrm{Te}_{2.7} \mathrm{Se}_{0.3}$ system [53]. Small polaron formation occurs more readily in disorder sites of the materials [54]. The impurity atom Sn overlaps on Bi sites, creates a defect state, and stays in the vicinity of the top of the valence band. These defect states absorb additional electrons or holes without shifting the Fermi energy too much. The activation energy of each of the samples is given in Table 5 .

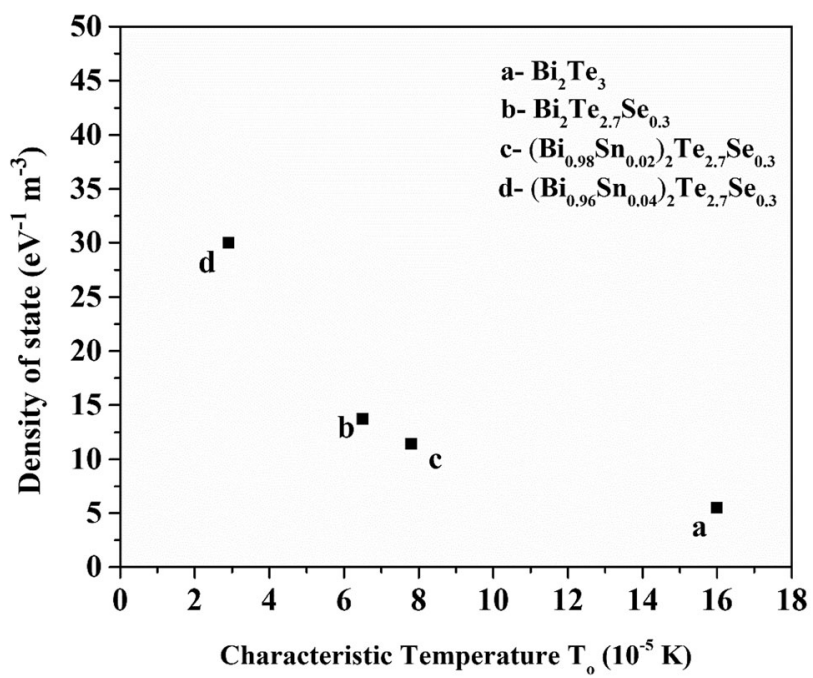

Fig. 13 Plot of Density of state versus characteristic temperature of $\left(\mathrm{Bi}_{1-x} \mathrm{Sn}_{x}\right)_{2} \mathrm{Te}_{2.7} \mathrm{Se}_{0.3}$



Fig. $14 \mathrm{SPH}$ fitting model for the single crystals $\left(\mathrm{Bi}_{1-x} \mathrm{Sn}_{x}\right)_{2}$ $\mathrm{Te}_{2.7} \mathrm{Se}_{0.3}$ at high temperatures

\subsection{Seebeck coefficient}

Figure 15 shows the temperature dependence of the Seebeck coefficient of the present samples in the range $10-395 \mathrm{~K}$. It is observed that all the grown crystals exhibit n-type semiconducting behavior due
Table 5 Calculation results of DOS of $\left(\mathrm{Bi}_{1-x} \mathrm{Sn}_{x}\right)_{2} \mathrm{Te}_{2.7} \mathrm{Se}_{0.3}$ at $300 \mathrm{~K}$

\begin{tabular}{llllc}
\hline Sample & $\begin{array}{l}\rho \text { at } 300 \mathrm{~K} \\
\Omega \mathrm{m}\end{array}$ & $\begin{array}{l}\alpha \\
\mathrm{nm}^{-1}\end{array}$ & $\begin{array}{l}T_{\mathrm{o}} \\
10^{-5} \\
(\mathrm{~K})\end{array}$ & $\begin{array}{l}N\left(E_{\mathrm{F}}\right) 10^{31} \\
\left(\mathrm{eV}^{-1} \mathrm{~m}^{-3}\right)\end{array}$ \\
\hline $\mathrm{Bi}_{2} \mathrm{Te}_{3}$ & & 36.2 & 16.0 & .5 .5 \\
$\mathrm{Bi}_{2} \mathrm{Te}_{2.7} \mathrm{Se}_{0.3}$ & $6.0 \times 10^{-5}$ & 16.3 & 6.5 & 13.7 \\
$\left(\mathrm{Bi}_{0.98} \mathrm{Sn}_{0.02}\right)_{2} \mathrm{Te}_{2.7} \mathrm{Se}_{0.3}$ & $2.6 \times 10^{-5}$ & 15.4 & 7.8 & 11.7 \\
$\left(\mathrm{Bi}_{0.96} \mathrm{Sn}_{0.04}\right)_{2} \mathrm{Te}_{2.7} \mathrm{Se}_{0.3}$ & $1.9 \times 10^{-5}$ & 11.2 & 2.9 & 30.0
\end{tabular}




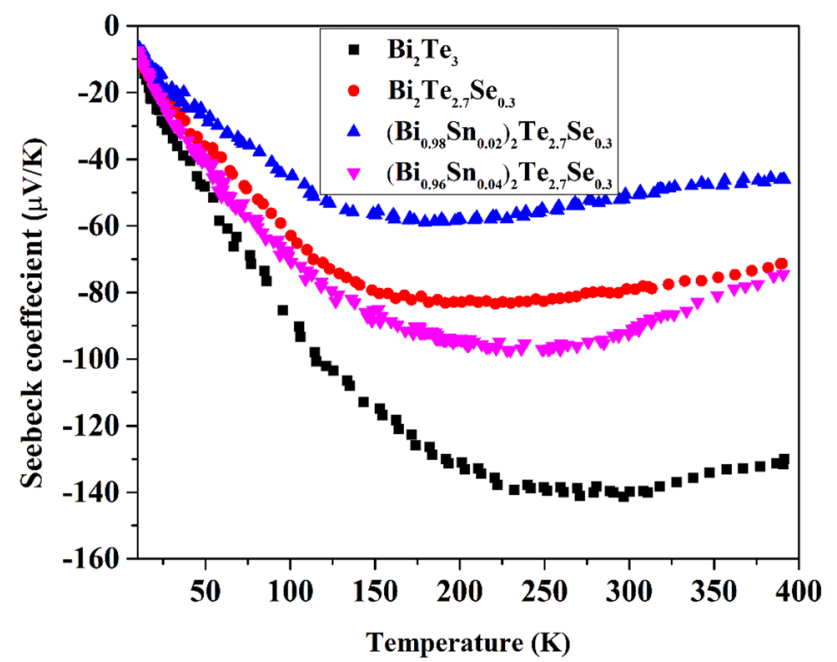

Fig. 15 Temperature-dependent Seebeck coefficient of $\left(\mathrm{Bi}_{1-x} \mathrm{Sn}_{x}\right)_{2}$ $\mathrm{Te}_{2.7} \mathrm{Se}_{0.3}$ single crystals

to antisite disorder $\mathrm{Te}_{\mathrm{Se}}-\mathrm{Bi}_{\mathrm{Sn}}$ and Te-Bi for the doped and pristine single crystal samples correspondingly. The magnitude of the Seebeck coefficient increases as the temperature increases from $10 \mathrm{~K}$ due to the generation of $\mathrm{Bi}_{\mathrm{Te}}$ defects. Sn exists in $\mathrm{Bi}_{2} \mathrm{Te}_{2.7} \mathrm{Se}_{0.3}$ in the polar form of $\mathrm{Sn}_{\mathrm{Bi}}$ bond. Bi-(Sn)-Te ${ }^{2}$ by Bi-(Sn)-Se ${ }^{2}$ are replaced by these polar bonds leading to the increase of antisite defects $[55,56]$. Seebeck coefficient value starts to saturate and decrease beyond $200 \mathrm{~K}$ due to the initiation of thermally excited holes, which neutralizes electrons with the formation of polar bonds in the pristine and co-doped samples [57]. It is observed that there is a decrease in the grain size as the number of grain boundaries subsequently increases. They act as a barrier and allow high energy charge carriers and restrict low energy charge carrier. Hence the average energy of charge carriers is increased, leading to enhancement in the Seebeck coefficient of polycrystalline $\left(\mathrm{Bi}_{0.96} \mathrm{Sn}_{0.04}\right)_{2} \mathrm{Te}_{2.7} \mathrm{Se}_{0.3}$ samples in our previous report. Whereas in single crystal $\left(\mathrm{Bi}_{0.96} \mathrm{Sn}_{0.04}\right)_{2} \mathrm{Te}_{2.7} \mathrm{Se}_{0.3}$, there are only few grain boundaries, the added $\mathrm{Sn}$ atom is assumed to occupy the lattice sites of $\mathrm{Bi}$. It is noticed that the electrons occupy the extended states of band. An active donor defect $S n_{B i}$ creates the distortion in the lattice structure. This gives rise to the degenerate behavior of electron concentrations in single crystal $\left(\mathrm{Bi}_{0.96} \mathrm{Sn}_{0.04}\right)_{2} \mathrm{Te}_{2.7} \mathrm{Se}_{0.3}$. The immediate formation of an intermediate band acting as balancing center of electrons and holes, which leads to limited excitement of carrier concentration [48,58]. This indicates that the added Sn has a significant impact on the carrier concentration throughout the temperature range. The dopant $S n$ is capable of suppressing the bond between $\mathrm{Bi}_{\mathrm{Te}}$ and $\mathrm{Bi}_{\mathrm{Se}}$ due to its higher electronegativity. The unusual decrease of the Seebeck coefficient values from pristine to the doped single crystal samples is because of formation of electronically active intrinsic disorder.

To understand the charge transport mechanism properly, hall voltage measurements were performed, which established the n-type semiconducting behavior of samples and provided experimentally measured value charge carrier concentration. The theoretical carrier concentration, on the other side, was estimated using [59]

$S(T)=\frac{8 k_{B}^{2} \pi^{2} m^{*}}{3 e h^{2}}\left(\frac{\pi}{3 n}\right)^{2 / 3} T$

$n$ is the carrier concentration, $m^{*}$ is the effective mass of an electron, and $e$ is the charge of an electron. Both theoretical and experimental carrier concentration values were predicted to be of identical order $\left(10^{25} \mathrm{~m}^{-3}\right)$. The theoretical mobility value was determined using

$\mu_{T h}=\frac{1}{n e \rho}$

Table 6 presents values of experimental and theoretical carrier concentrations, mobility, and scattering factor. The production of $V_{\ddot{T} e}$ and $V_{\ddot{S} e}$ (Te and Se vacancies) could be the reason behind the random variation in values $\mu_{T h}$. Electrons having different effective masses carry different quantities of current under various conditions of doping. Hence, the time of relaxation and nature of scattering of electrons varies with changes in doping levels. With the assistance of experimental carrier mobility, weighted mobility $\left(\mu_{w}\right)$ were determined utilizing [60]

$\mu_{w}=\left(\mu\left(\frac{m^{*}}{m_{e}}\right)^{\frac{3}{2}}\right)$

Due to the high concentration of ionized impurities, including acceptors and donors, antisite defects are produced on $\mathrm{Te}(\mathrm{Se})$ atoms by $\mathrm{Bi}(\mathrm{Sn})$ in $\left(\mathrm{Bi}_{1-x}\right.$ $\mathrm{Sn})_{x} \mathrm{Te}_{2.7} \mathrm{Se}_{0.3}$ layered crystals. Moreover, there are excess negative charges in the nearby sites and many vacant sites, making the single crystal exhibit n-type semiconducting behavior. The effective mass is determined by employing Eq. (8) and presented in 
Table 6 Experimental $\left(n_{\text {Exp }}\right)$, theoretical carrier concentration $\left(n_{T h}\right)$, experimental $\left(\mu_{\mathrm{Exp}}\right)$ and theoretical $\left(\mu_{T \mathrm{~h}}\right)$ carrier mobility, experimental $\left(\gamma_{\operatorname{Exp}}\right)$, theoretical $\left(\gamma_{\mathrm{Th}}\right)$ carrier scattering factor, effective mass $\left(m^{*}\right)$, weighted mobility $\left(\mu_{\mathrm{w}}\right)$, Fermi energy $\left(E_{F}\right)$, pre-exponential factor $\left(\rho_{0}\right)$, activation energy $\left(E_{A}\right)$ of the single crystals $\left(\mathrm{Bi}_{1-x} \mathrm{Sn}_{x}\right)_{2} \mathrm{Te}_{2.7} \mathrm{Se}_{0.3}$

\begin{tabular}{|c|c|c|c|c|c|c|c|c|c|c|c|}
\hline Sample & $\begin{array}{l}n_{\mathrm{Th}} \\
10^{25} \\
\left(\mathrm{~m}^{-3}\right)\end{array}$ & $\begin{array}{l}n_{\operatorname{Exp}} \\
10^{25} \\
\left(\mathrm{~m}^{-3}\right)\end{array}$ & $\begin{array}{c}\mu_{T \mathrm{~h}} \\
10^{-4} \\
\left(\mathrm{~m}^{2} /\right. \\
\mathrm{Vs})\end{array}$ & $\begin{array}{l}\mu_{\operatorname{Exp}} \\
10^{-4}\left(\mathrm{~m}^{2} /\right. \\
\mathrm{Vs})\end{array}$ & $\gamma_{\mathrm{Th}}$ & $\gamma_{\operatorname{Exp}}$ & $\begin{array}{l}m^{*} \\
\left(\mathrm{~m}_{\mathrm{e}}\right)\end{array}$ & $\begin{array}{c}\left(\mu_{\mathrm{w}}\right) \\
10^{-4}\left(\mathrm{~m}^{2} /\right. \\
\mathrm{Vs})\end{array}$ & $\begin{array}{l}E_{\mathrm{F}} \\
(\mathrm{eV})\end{array}$ & $\begin{array}{l}E_{\mathrm{A}} \\
(\mathrm{meV})\end{array}$ & $\begin{array}{l}\rho_{0} \\
10^{-5} \\
(\Omega \mathrm{m})\end{array}$ \\
\hline $\mathrm{Bi}_{2} \mathrm{Te}_{3}$ & 5.4 & 6.7 & 6.0 & 9.4 & 59.2 & 59.4 & 5.6 & 4.3 & 0.05 & 15.0 & 5.1 \\
\hline $\mathrm{Bi}_{2} \mathrm{Te}_{2.7} \mathrm{Se}_{0.3}$ & 13.0 & 11.0 & 20.0 & 18.0 & 60.1 & 58.9 & 2.4 & 9.3 & 0.09 & 19.0 & 3.3 \\
\hline$\left(\mathrm{Bi}_{0.98} \mathrm{Sn}_{0.02}\right)_{2} \mathrm{Te}_{2.7} \mathrm{Se}_{0.3}$ & 3.57 & 3.9 & 82.0 & 71.0 & 58.8 & 60.0 & 9.2 & 17.8 & 0.04 & 19.5 & 2.3 \\
\hline$\left(\mathrm{Bi}_{0.96} \mathrm{Sn}_{0.04}\right)_{2} \mathrm{Te}_{2.7} \mathrm{Se}_{0.3}$ & 10.9 & 2.0 & 32.0 & 8.0 & 59.9 & 58.2 & 5.6 & 3.2 & 0.08 & 18.9 & 2.0 \\
\hline
\end{tabular}

Table 6. The Fermi energy $\left(E_{\mathrm{F}}\right)$ of compounds is determined utilizing

$E_{F}=-\frac{\pi^{2} k_{B}^{2} T}{3 e S}$

When the electronically active element $\mathrm{Sn}$ is doped in the $\mathrm{Bi}_{2} \mathrm{Te}_{3}$ single crystals, they create active intrinsic donor or accepter type defects. This shifts the Fermi-level in the vicinity of the density of states results in an uneven variation of the population with respect to temperature and doping [61]. Generation of antisite defects of $\mathrm{Bi}_{\mathrm{Sn}}$ on the $\mathrm{Te}_{\mathrm{Se}}$ site leads to super stoichiometry, which encourages lattice scattering [62]. The lattice of crystal comprises antisite defects of negatively charged sites of $\mathrm{Bi}(\mathrm{Sn})_{\mathrm{Se}}$ and $\mathrm{Bi}(\mathrm{Sn})_{\mathrm{Te}}$ vacancies of positively charged in tellurium sublattice $V_{\ddot{T} e}$ and $V_{\ddot{S} e}$. The concentration of $V_{\ddot{T} e}$ and $V_{\ddot{S} e}$ surpasses the number of antisite defects. Hence Fermi energy has not shown any specific variation of trend as a function of composition in current compounds. The scattering factor $(\gamma)$ was calculated using [63]

$\gamma=\ln n+S$

Fermi-energy and values of theoretical and experimental scattering factors are presented in Table 6.

\subsection{Thermal conductivity}

The temperature dependence of thermal conductivity of grown single crystals in the temperature between 10 and $395 \mathrm{~K}$ is revealed in Fig. 16. All crystals exhibit a sharp enhancement of thermal conductivity with increasing temperature between 10 and $50 \mathrm{~K}$ because of restraining the mean phonons free path

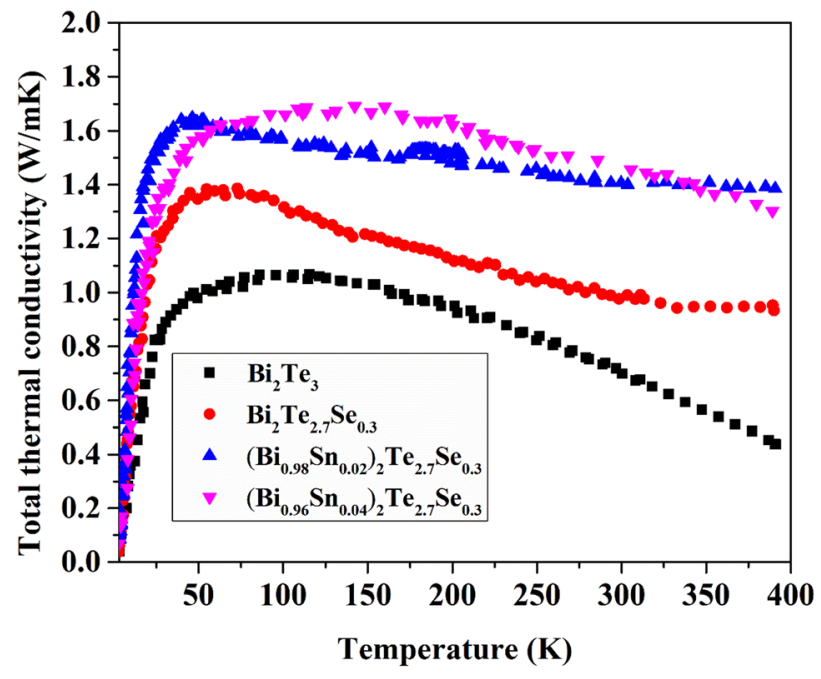

Fig. 16 Total (measured) thermal conductivity of $\left(\mathrm{Bi}_{1-x} \mathrm{Sn}_{x}\right)_{2}$ $\mathrm{Te}_{2.7} \mathrm{Se}_{0.3}$ single crystal

length through low angle grain boundaries by specular reflection [64]. The highest and lowest thermal conductivity values were observed in single crystal $\left(\mathrm{Bi}_{0.96} \mathrm{Sn}_{0.04}\right)_{2} \mathrm{Te}_{2.7} \mathrm{Se}_{0.3}$ and $\mathrm{Bi}_{2} \mathrm{Te}_{3}$ samples, respectively, between 50 and $360 \mathrm{~K}$. The co-doped extrinsic regime is preferred by low vacancy energy formation. The small bandgap in the material hinders thermal conductivity towards room temperature by forming bipolar conduction. Hence there is a crossing over of total thermal conductivity value of $\left(\mathrm{Bi}_{0.96} \mathrm{Sn}_{0.04}\right)_{2-}$ $\mathrm{Te}_{2.7} \mathrm{Se}_{0.3}$ by $\left(\mathrm{Bi}_{0.98} \mathrm{Sn}_{0.02}\right)_{2} \mathrm{Te}_{2.7} \mathrm{Se}_{0.3}$ [65].

The contribution of electronic heat transport $\kappa_{e}$ is determined by Wiedemann-Franz law $\left(\kappa_{e}=\frac{L_{0} T}{\rho}\right)$ where $L_{0}$ is temperature-dependent Lorentz number and is determined utilizing [60] (Fig. 17). 


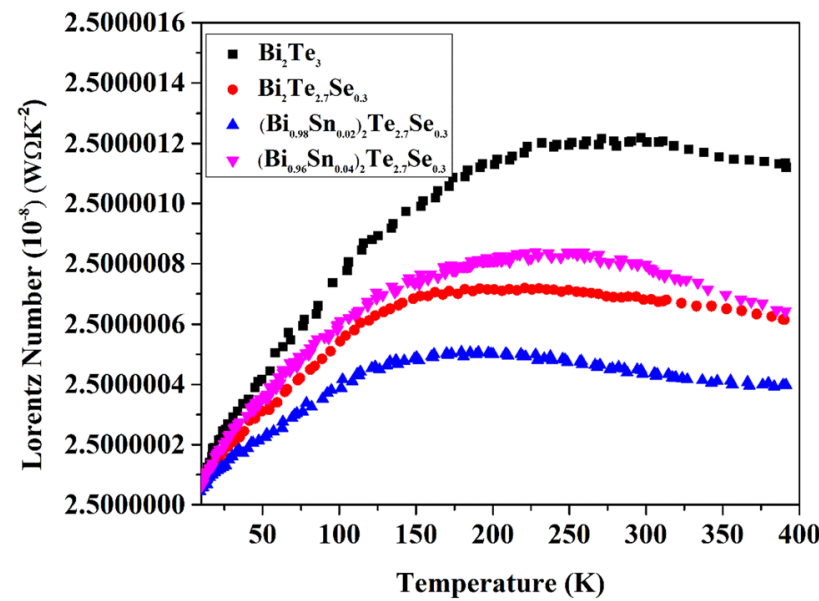

Fig. 17 Lorentz numbers of single crystal $\left(\mathrm{Bi}_{1-x} \mathrm{Sn}_{x}\right)_{2} \mathrm{Te}_{2.7} \mathrm{Se}_{0.3}$

$L_{0}=1.5+\frac{\exp (-|s|)}{116}$

The lattice component of thermal conductivity (Fig. 18) $\left(\kappa_{l}\right)$ is calculated by subtracting electronic thermal conductivity [Fig. 19] from total thermal conductivity $(\kappa)$. Values of $\kappa_{l}$ Change as $1 / T$ above $50 \mathrm{~K}$ in doped compounds due to greater possibility of Umklapp process. The significant concentration of doping in $\mathrm{Bi}_{2} \mathrm{Te}_{3}$ results in charge transfer, phonon Umklapp scattering, and point defect scattering. It is observed that the main contribution to measure $\kappa(T)$ initiates from phononic components rather than charge carriers.

The experimental values of thermal conductivities imply that some minor additional holes are created

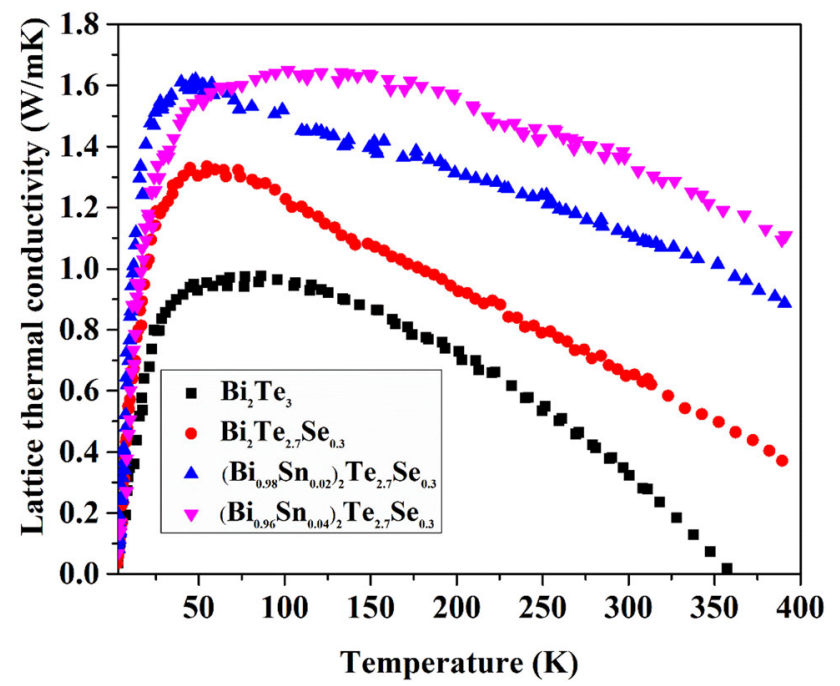

Fig. 18 Lattice thermal conductivity $\left(\kappa_{l}\right)$ of single crystal $\left(\mathrm{Bi}_{1-x} \mathrm{Sn}_{x}\right)_{2} \mathrm{Te}_{2.7} \mathrm{Se}_{0.3}$

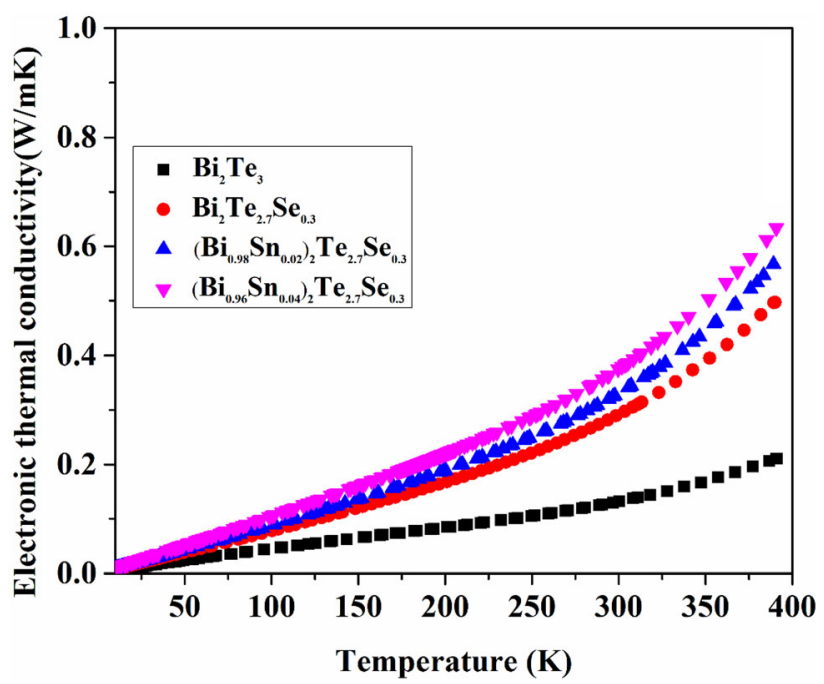

Fig. 19 Temperature-dependent electronic thermal conductivity $\left(\kappa_{e}\right)$ of single crystal $\left(\mathrm{Bi}_{1-x} \mathrm{Sn}_{x}\right)_{2} \mathrm{Te}_{2.7} \mathrm{Se}_{0.3}$

due to the doping of Sn. Because of the effect of differences in mass and lattice constants among the dopants $\mathrm{Sn}$ and Se over $\mathrm{Bi}$ and $\mathrm{Te}$, there is an expectation of a probable disorder by the intercalation of Sn and Te/Se [66]. Thus, modification of distortion could deteriorate the phonon scattering and enhance thermal conductivity with respect to doping concentration [67]. As $\left(\mathrm{Bi}_{1-x} \mathrm{Sn}_{x}\right)_{2} \mathrm{Te}_{2.7} \mathrm{Se}_{0.3}$ shows semiconducting behavior of n-type, heat flow is monodirectional, only because of free electron density [68]. The present reported thermal conductivity of single crystal $\mathrm{Bi}_{2} \mathrm{Te}_{3}$ shows a decrease in thermal conductivity $(0.6 \mathrm{~W} / \mathrm{mK})$ in comparison to our

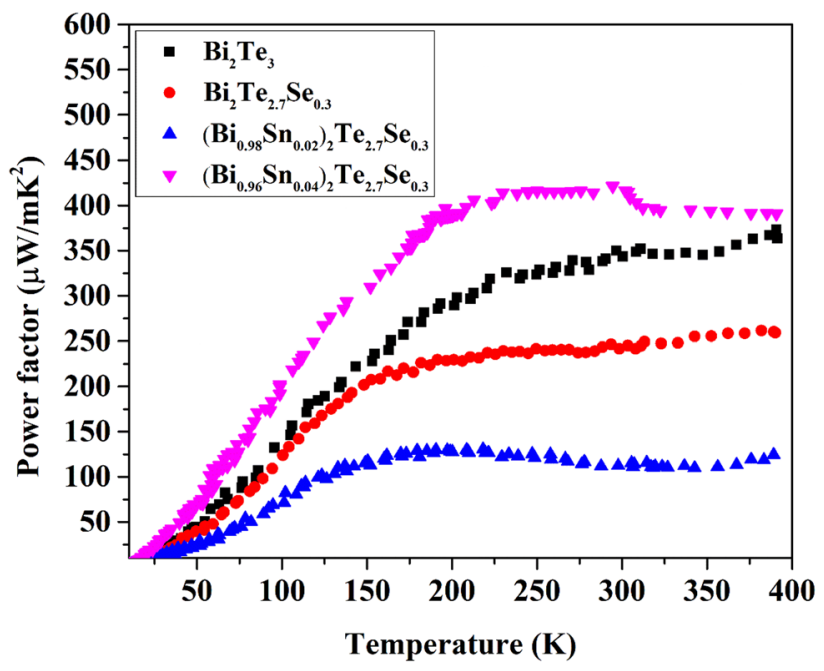

Fig. 20 Temperature-dependent power factor (PF) of single crystal $\left(\mathrm{Bi}_{1-x} \mathrm{Sn}_{x}\right)_{2} \mathrm{Te}_{2.7} \mathrm{Se}_{0.3}$ 




Fig. 21 Temperature-dependent thermoelectric figure of merit (ZT) of single crystal $\left(\mathrm{Bi}_{1-x} \mathrm{Sn}_{x}\right)_{2} \mathrm{Te}_{2.7} \mathrm{Se}_{0.3}$

previously reported polycrystal $\mathrm{Bi}_{2} \mathrm{Te}_{3}(3.0 \mathrm{~W} / \mathrm{mK})$ at $300 \mathrm{~K}$ [16] due to the peierls distortion [69]. In polycrystalline $\mathrm{Bi}_{2} \mathrm{Te}_{3}$, a charge density wave system encourages strong electron-phonon coupling which weakens the effect of the Peierls distortion on the mechanism of lattice thermal conductivity. As a result of decrease in an harmonicity of polycrystalline samples leading to higher lattice thermal conductivity than the single crystals. The low lattice thermal conductivity in single crystal $\mathrm{Bi}_{2} \mathrm{Te}_{3}$ originate from the quantum confinement effect and the charge density wave induced by Periels distortion. It has been revealed that materials form resonant bonding like $\mathrm{Bi}-\mathrm{Te}$ in pristine $\mathrm{Bi}_{2} \mathrm{Te}_{3}$ single crystal. Usually the single crystal chalchogenides have long-ranged interactions in hexagonal structure. This leads to the strong an-harmonic scattering with different phonon mean-free path results in low value of lattice thermal conductivity [70]. As the anisotropic transport property is exhibited by polycrystalline samples, phonon scattering dominates in the disordered lattice.

\subsection{Thermoelectric power factor (PF) and figure of merit (ZT)}

Figure 20 displays the temperature-dependent power factor $\left(P F=S^{2} / \rho\right)$ of present single crystals. Because of the significant variation in Seebeck coefficient and electrical resistivity, it was observed that the $P F$ value of $\left(\mathrm{Bi}_{0.96} \mathrm{Sn}_{0.02}\right)_{2} \mathrm{Te}_{2.7} \mathrm{Se}_{0.3}\left(390 \mu \mathrm{W} / \mathrm{mK}^{2}\right)$ is 1.1 times greater than that of pristine $\left(330 \mu \mathrm{W} / \mathrm{mK}^{2}\right)$. The variation of thermoelectric figure of merit for $\left(\mathrm{Bi}_{1-x-}\right.$ $\left.\mathrm{Sn}_{x}\right)_{2} \mathrm{Te}_{2.7} \mathrm{Se}_{0.3}$ is shown in Fig. 21. The highest $\mathrm{ZT}$ value of 0.34 is observed for $\mathrm{Bi}_{2} \mathrm{Te}_{3}$. Though there is a systematic decrease in electrical resistivity of single crystal series $\left(\mathrm{Bi}_{1-x} \mathrm{Sn}_{x}\right)_{2} \mathrm{Te}_{2.7} \mathrm{Se}_{0.3}$, due to the significant variation in Seebeck coefficient and thermal conductivity, the ZT value has been decreased for codoped samples. The values of $Z T$ of some standard reported compounds are given in Table 7.

\section{Conclusion}

Thermoelectric investigation of $\left(\mathrm{Bi}_{1-x} \mathrm{Sn}_{x}\right)_{2} \mathrm{Te}_{2.7} \mathrm{Se}_{0.3}$ single crystals was carried in the low temperature range $10-400 \mathrm{~K}$. Powder XRD analysis confirms hexagonal crystal system with $\mathrm{R} \overline{3} m$ space group. The HRXRD technique confirms " $c$ " directional growth with small-angle tilt boundaries and rotational threefold symmetry of crystals. The surface morphology exhibits porous free surface with a slight tilt angle and selenium volatilization. EDAX confirms the homogeneous distribution of single crystal elemental compositions. A major reduction in electrical resistivity of 3.3 times for $\left(\mathrm{Bi}_{0.96} \mathrm{Sn}_{0.04}\right)_{2} \mathrm{Te}_{2.7} \mathrm{Se}_{0.3}$ in comparison with pristine was observed at $400 \mathrm{~K}$. A considerable decrease in electrical resistivity was observed for co-doped $\left(\mathrm{Bi}_{0.96} \mathrm{Sn}_{0.04}\right)_{2} \mathrm{Te}_{2 \cdot 7} \mathrm{Se}_{0.3}$ single crystal results in an enhancement $\mathrm{PF}$ value by a factor of 1.1 as compared to $\mathrm{Bi}_{2} \mathrm{Te}_{3}$.
Table $7 \mathrm{ZT}$ value of some reported $\mathrm{Bi}_{2} \mathrm{Te}_{3}$ based compounds

\begin{tabular}{llll}
\hline Compound & Method & ZT & $\mathrm{T}(\mathrm{K})$ \\
\hline $\mathrm{Bi}_{2} \mathrm{Te}_{3}[71]$ & Spark plasm sintering & 0.29 & 300 \\
"Bi-Te $+\mathrm{Bi}-\mathrm{Te}-\mathrm{Se}$ " [72] & Solvothermal & 0.05 & 300 \\
$\mathrm{Bi}_{2} \mathrm{Se}_{2.7} \mathrm{Te}_{0.3}[73]$ & Melt growth & 0.10 & 300 \\
$\left(\mathrm{Bi}_{0.98} \mathrm{Sn}_{0.02}\right)_{2} \mathrm{Te}_{2.7} \mathrm{Se}_{0.3}[16]$ & Solid state reaction & 0.27 & 300 \\
"Bi-Te-Se alloys" [74] & Thin film technique & 0.20 & 300 \\
$\mathrm{Bi}_{2} \mathrm{Te}_{3} *$ & Melt growth & 0.34 & 400 \\
\hline
\end{tabular}

*Present work 


\section{Acknowledgements}

Ganesh Shridhar Hegde (GSH) likes to acknowledge the Manipal Academy of Higher Education for delivering financial support from the doctoral fellowship of Dr. T. M. A. Pai. GSH would like to show gratitude towards Mr. Srihari N. V., Mr. Manoj S.P., Mr. Pawan Acharya for their co-operation. ANP is thankful for the financial support provided by UGCDAE, Mumbai, under the project Grant of UDCSR/ MUM/AO/CRS-M-314/2020/812. The authors want to express their gratitude towards UGC DAE personnel Dr. V. Raghavendra reddy for providing the HRXRD facility. The authors also would like to thank Dr. Dhananjaya Kekuda Dr. Mahesha M. G for their help and co-operation.

\section{Author contributions}

GSH: methodology, writing original draft. ANP: supervision, writing review and editing. MKC: resources, validation, writing review and editing.

\section{Funding}

Open access funding provided by Manipal Academy of Higher Education, Manipal. Not applicable.

\section{Data availability}

Not applicable.

\section{Code availability}

Not applicable.

\section{Declarations}

Conflict of interest All authors certify that they have no affiliations with or involvement in any organization or entity with any financial interest or non-financial interest in the subject matter or materials discussed in this manuscript.

Open Access This article is licensed under a Creative Commons Attribution 4.0 International License, which permits use, sharing, adaptation, distribution and reproduction in any medium or format, as long as you give appropriate credit to the original author(s) and the source, provide a link to the Creative Commons licence, and indicate if changes were made. The images or other third party material in this article are included in the article's Creative Commons licence, unless indicated otherwise in a credit line to the material. If material is not included in the article's Creative Commons licence and your intended use is not permitted by statutory regulation or exceeds the permitted use, you will need to obtain permission directly from the copyright holder. To view a copy of this licence, visit http://creativecommons.org/licen ses/by $/ 4.0 /$.

\section{References}

1. K.C. Kim, B. Kwon, H.J. Kim, S.H. Baek, D. Bin Hyun, S.K. Kim, J.S. Kim, Appl. Surf. Sci. 353, 232 (2015)

2. M.K. Zhitinskaya, S.A. Nemov, T.E. Svechnikova, Phys. Solid State 40, 1297 (1998)

3. V.A. Kulbachinskii, V.G. Kytin, A.A. Kudryashov, P.M. Tarasov, J. Solid State Chem. 193, 47 (2012)

4. S.K. Kushwaha, I. Pletikosić, T. Liang, A. Gyenis, S.H. Lapidus, Y. Tian, H. Zhao, K.S. Burch, J. Lin, W. Wang, H. Ji, A.V. Fedorov, A. Yazdani, N.P. Ong, T. Valla, R.J. Cava, Nat. Commun. 7, 11456 (2016)

5. Z. Zhang, Y. Cao, Q. Tao, Y. Yan, X. Su, X. Tang, J. Solid State Chem. 292, 121722 (2020)

6. S. Nakajima, J. Phys. Chem. Solids 24, 479 (1963)

7. A. Krishna, N. Vijayan, B. Singh, K. Thukral, K.K. Maurya, Mater. Sci. Eng. A 657, 33 (2016)

8. R.-S. Zhai, Y.-H. Wu, T.-J. Zhu, X.-B. Zhao, Rare Met. 37, 308 (2018)

9. M.Z. Tahar, S.A. Nemov, D.I. Popov, T.E. Svechnikova, J. Phys. Conf. Ser. 150, 022082 (2009)

10. M.-K. Han, J. Hwang, S.-J. Kim, J. Mater. Sci. Mater. Electron. 30, 1282 (2019)

11. I.T. Witting, F. Ricci, T.C. Chasapis, G. Hautier, G.J. Snyder, Research 2020, 1 (2020)

12. S.K. Kushwaha, Q.D. Gibson, J. Xiong, I. Pletikosic, A.P. Weber, A.V. Fedorov, N.P. Ong, T. Valla, R.J. Cava, J. Appl. Phys. 115, 143708 (2014)

13. M.K. Zhitinskaya, S.A. Nemov, T.E. Svechnikova, Mater. Sci. Semicond. Process. 6, 449 (2003)

14. Z. Ren, A.A. Taskin, S. Sasaki, K. Segawa, Y. Ando, Phys. Rev. B 85, 1 (2012)

15. B. Wiendlocha, J. Electron. Mater. 45, 3515 (2016)

16. G.S. Hegde, A.N. Prabhu, A. Rao, M.K. Chattopadhyay, Mater. Sci. Semicond. Process. 127, 105645 (2021) 
17. T. Mori, J.-B. Vaney, G. Guélou, F. Failamani, Q. Guo, Cryst. Growth Intermet. Thermoelectr. Mater. (2018). https://doi.org/ $10.1515 / 9783110496789$

18. G.S. Hegde, A.N. Prabhu, A. Rao, P.D. Babu, Physica B 584, 412087 (2020)

19. G.S. Hegde, A.N. Prabhu, R.Y. Huang, Y.K. Kuo, J. Mater. Sci. Mater. Electron. 31, 19511 (2020)

20. A. Subrati, Y. Kim, Y. Al Wahedi, V. Tzitzios, S. Alhassan, H.J. Kim, S. Lee, E. Sakellis, N. Boukos, S. Stephen, S.M. Lee, J.B. Lee, M. Fardis, G. Papavassiliou, CrystEngComm 22, 7918 (2020)

21. O. Falkenbach, M.O. Loeh, C.W. Wiegand, A. Schmitz, D. Hartung, G. Koch, P.J. Klar, E. Mueller, S. Schlecht, J. Electron. Mater. 46, 5781 (2017)

22. I. Terasaki, The Reference Module in Materials Science and Materials Engineering (Elsevier, Amsterdam, 2016), pp. $1-40$

23. A. Knauer, J. Kräusslich, R. Kittner, R. Staske, A. Bärwolff, Cryst. Res. Technol. 25, 441 (1990)

24. C.I. Fornari, P.H.O. Rappl, S.L. Morelhão, G. Fornari, J.S. Travelho, S. De Castro, M.J.P. Pirralho, F.S. Pena, M.L. Peres, E. Abramof, Mater. Res. Express 5, 116410 (2018)

25. V.V. Atuchin, V.A. Golyashov, K.A. Kokh, I.V. Korolkov, A.S. Kozhukhov, V.N. Kruchinin, I.D. Loshkarev, L.D. Pokrovsky, I.P. Prosvirin, K.N. Romanyuk, O.E. Tereshchenko, J. Solid State Chem. 236, 203 (2016)

26. S. Dey, N. Gayathri, M. Bhattacharya, P. Mukherjee, Metall. Mater. Trans. A 47, 6281 (2016)

27. G.S. Hegde, A.N. Prabhu, Y.H. Gao, Y.K. Kuo, V.R. Reddy, J. Alloys Compd. 866, 158814 (2021)

28. J. Kim, C. Bayram, H. Park, C.W. Cheng, C. Dimitrakopoulos, J.A. Ott, K.B. Reuter, S.W. Bedell, D.K. Sadana, Nat. Commun. 5, 1 (2014)

29. M. Rathi, P. Dutta, N. Zheng, Y. Yao, D. Khatiwada, A. Khadimallah, Y. Gao, S. Sun, Y. Li, S. Pouladi, P. Ahrenkiel, J.H. Ryou, V. Selvamanickam, J. Mater. Chem. C 5, 7919 (2017)

30. V.K. Dixit, S. Kumar, S.D. Singh, S.K. Khamari, R. Kumar, P. Tiwari, D.M. Phase, T.K. Sharma, S.M. Oak, Appl. Phys. Lett. 104, 092101 (2014)

31. D. Kumar, A. Lakhani, Mater. Res. Bull. 88, 127 (2017)

32. D. Kumar, A. Lakhani, Phys. Status Solidi-Rapid Res. Lett. 9, $636(2015)$

33. G. Bhagavannarayana, R.V. Ananthamurthy, G.C. Budakoti, B. Kumar, K.S. Bartwal, J. Appl. Crystallogr. 38, 768 (2005)

34. M. Shkir, V. Ganesh, S. Alfaify, A. Black, E. Dieguez, K.K. Maurya, Cryst. Growth Des. 18, 2046 (2018)

35. J.Q. Liu, J.F. Wang, Y.F. Liu, K. Huang, X.J. Hu, Y.M. Zhang, Y. Xu, K. Xu, H. Yang, J. Cryst. Growth 311, 3080 (2009)
36. K. Wang, C. Steimer, D. Wamwangi, S. Ziegler, M. Wuttig, Appl. Phys. A 80, 1611 (2005)

37. A.H. Ali, A. Shuhaimi, H. Zainuriah, Y. Yusof, Adv. Mater. Res. 620, 22 (2012)

38. S. Aminorroaya Yamini, M. Brewis, J. Byrnes, R. Santos, A. Manettas, Y.Z. Pei, J. Mater. Chem. C 3, 10610 (2015)

39. Z.L. Wang, T. Araki, T. Onda, Z.C. Chen, J. Mater. Sci. 53, 9117 (2018)

40. A.H. Ali, A. Shuhaimi, Z. Hassan, Y. Yusof, Adv. Mater. Res. 620, 22 (2013)

41. S. Wang, H. Li, R. Lu, G. Zheng, X. Tang, Nanotechnology 24, 285702 (2013)

42. S. Mukherjee, O.E. Femi, R. Chetty, K. Chattopadhyay, S. Suwas, R.C. Mallik, Appl. Surf. Sci. 449, 805 (2018)

43. V. Thakur, K. Upadhyay, R. Kaur, N. Goyal, S. Gautam, Mater. Today Adv. 8, 100082 (2020)

44. Y. Sun, H. Cheng, S. Gao, Q. Liu, Z. Sun, C. Xiao, C. Wu, S. Wei, Y. Xie, J. Am. Chem. Soc. 134, 20294 (2012)

45. B. Jariwala, D. Shah, N.M. Ravindra, J. Electron. Mater. 44, 1509 (2015)

46. M.W. Oh, J.H. Son, B.S. Kim, S.D. Park, B.K. Min, H.W. Lee, J. Appl. Phys. 115, 13 (2014)

47. Q. Zhang, B. Gu, Y. Wu, T. Zhu, T. Fang, Y. Yang, J. Liu, B. Ye, X. Zhao, ACS Appl. Mater. Interfaces 11, 41424 (2019)

48. X. Hu, Q. Xiang, D. Kong, X. Fan, B. Feng, Z. Pan, P. Liu, R. Li, G. Li, Y. Li, J. Solid State Chem. 277, 175 (2019)

49. D.J. Ryden, J. Phys. C 4, 1193 (1971)

50. E. Lee, J. Il Kim, S.M. Choi, Y.S. Lim, W.S. Seo, J.Y. Kim, K.H. Lee, J. Nanomater. (2015). https://doi.org/10.1088/002 2-3719/4/10/027

51. O. Ivanov, M. Yaprintsev, E. Danshina, Physica B 545, 222 (2018)

52. K. Shyam Prasad, A. Rao, B. Christopher, R. Bhardwaj, N.S. Chauhan, S.A. Malik, N. Vannong, B.S. Nagaraja, R. Thomas, J. Alloys Compd. 748, 273 (2018)

53. I. Ahmad, M.J. Akhtar, M. Younas, M. Siddique, M.M. Hasan, J. Appl. Phys. 112, 074105 (2012)

54. J. Schnakenberg, Phys. Status Solidi B 28, 623 (1968)

55. G.M. Guttmann, D. Dadon, Y. Gelbstein, J. Appl. Phys. 118, $065102(2015)$

56. Y. Zhang, L.P. Hu, T.J. Zhu, J. Xie, X.B. Zhao, Cryst. Growth Des. 13, 645 (2013)

57. T.E. Svechnikova, I.Y. Nikhezina, N.V. Polikarpova, Inorg. Mater. 36, 765 (2000)

58. X. Hou, S. Chen, Z. Du, X. Liu, J. Cui, RSC Adv. 5, 102856 (2015)

59. K. Shyam Prasad, A. Rao, K. Tyagi, N. Singh Chauhan, B. Gahtori, S. Bathula, A. Dhar, Physica B 512, 39 (2017)

60. K. Gurukrishna, A. Rao, Z.Z. Jiang, Y.K. Kuo, Intermetallics 122, 106803 (2020) 
61. M.K. Zhitinskaya, S.A. Nemov, T.E. Svechnikova, P. Reinshaus, E. Müller, Semiconductors 34, 1363 (2000)

62. J. Horák, J. Navrátil, Z. Starý, J. Phys. Chem. Solids 53, 1067 (1992)

63. E. Witkoske, X. Wang, M. Lundstrom, V. Askarpour, J. Maassen, J. Appl. Phys. 122, 175102 (2017)

64. R. Thomas, A. Rao, R. Bhardwaj, L.Y. Wang, Y.K. Kuo, Mater. Res. Bull. 120, 110607 (2019)

65. H. Shi, D. Parker, M.-H. Du, D.J. Singh, Phys. Rev. Appl. 3, 014004 (2015)

66. S.Y. Kim, H.S. Kim, K.H. Lee, H. Cho, S. Choo, S. Hong, Y. Oh, Y. Yang, K. Lee, J.H. Lim, S.M. Choi, H.J. Park, W.H. Shin, S. Kim, Materials (Basel) (2019). https://doi.org/10.33 90/ma12244080

67. F. Li, M. Ruan, Y. Chen, W. Wang, J. Luo, Z. Zheng, P. Fan, Inorg. Chem. Front. 6, 799 (2019)

68. J.U. Lee, D.H. Lee, B. Kwon, D. Binhyun, S. Nahm, S.H. Baek, J.S. Kim, J. Electron. Mater. 44, 1926 (2015)
69. J.-S. Rhyee, D. Choi, J. Appl. Phys. 110, 083706 (2011)

70. C. Tang, Z. Huang, J. Pei, B.P. Zhang, P.P. Shang, Z. Shan, Z. Zhang, H. Gu, K. Wen, RSC Adv. 9, 14422 (2019)

71. Y. Pan, T.-R. Wei, C.-F. Wu, J.-F. Li, J. Mater. Chem. C 3, $10583(2015)$

72. X.H. Ji, X.B. Zhao, Y.H. Zhang, B.H. Lu, H.L. Ni, Mater. Lett. 59, 682 (2005)

73. A.M. Adam, A. Elshafaie, A.E.-M.A. Mohamed, P. Petkov, E.M.M. Ibrahim, Mater. Res. Express 5, 035514 (2018)

74. A.M. Adam, A. El-Khouly, E. Lilov, S. Ebrahim, Y. Keshkh, M. Soliman, E.M. El Maghraby, V. Kovalyo, P. Petkov, Mater. Chem. Phys. 224, 264 (2019)

Publisher's Note Springer Nature remains neutral with regard to jurisdictional claims in published maps and institutional affiliations. 